IZA DP No. 9167

Investment over the Business Cycle:

Insights from College Major Choice

Erica Blom

Brian C. Cadena

Benjamin J. Keys

July 2015 


\title{
Investment over the Business Cycle: Insights from College Major Choice
}

\author{
Erica Blom \\ Edgeworth Economics \\ Brian C. Cadena \\ University of Colorado Boulder \\ and IZA \\ Benjamin J. Keys \\ University of Chicago
Discussion Paper No. 9167
July 2015 \\ IZA \\ P.O. Box 7240 \\ 53072 Bonn \\ Germany \\ Phone: +49-228-3894-0 \\ Fax: +49-228-3894-180 \\ E-mail: iza@iza.org
}

\begin{abstract}
Any opinions expressed here are those of the author(s) and not those of IZA. Research published in this series may include views on policy, but the institute itself takes no institutional policy positions. The IZA research network is committed to the IZA Guiding Principles of Research Integrity.

The Institute for the Study of Labor (IZA) in Bonn is a local and virtual international research center and a place of communication between science, politics and business. IZA is an independent nonprofit organization supported by Deutsche Post Foundation. The center is associated with the University of Bonn and offers a stimulating research environment through its international network, workshops and conferences, data service, project support, research visits and doctoral program. IZA engages in (i) original and internationally competitive research in all fields of labor economics, (ii) development of policy concepts, and (iii) dissemination of research results and concepts to the interested public.
\end{abstract}

IZA Discussion Papers often represent preliminary work and are circulated to encourage discussion. Citation of such a paper should account for its provisional character. A revised version may be available directly from the author. 


\section{ABSTRACT \\ Investment over the Business Cycle: Insights from College Major Choice*}

This paper examines the relationship between individuals' personal exposure to economic conditions and their investment choices in the context of human capital. Focusing on bachelor's degree recipients, we find that birth cohorts exposed to higher unemployment rates during typical schooling years select majors that earn higher wages, that have better employment prospects, and that more often lead to work in a related field. Much of this switching behavior can be considered a rational response to differences in particular majors' labor market prospects during a recession. However, higher unemployment leads to other meaningful changes in the distribution of majors. Conditional on changes in lifetime expected earnings, recessions encourage women to enter male-dominated fields, and students of both genders pursue more difficult majors, such as STEM fields. These findings imply that the economic environment changes how students select majors, possibly by encouraging them to consider a broader range of possible degree fields. Finally, in the absence of this compensating behavior, we estimate that the average estimated costs of graduating in a recession would be roughly ten percent larger.

JEL Classification: $\quad$ E32, I23, J22, J24

Keywords: college major, business cycle, human capital investment, STEM majors, gender differences

Corresponding author:

Brian C. Cadena

Department of Economics

University of Colorado

256 UCB

Boulder, CO 80309

USA

E-mail: brian.cadena@colorado.edu

\footnotetext{
"We thank Lisa Kahn, Ofer Malamud, Thomas Lemieux and seminar participants at the Upjohn Institute and the University of Colorado-Boulder for helpful comments. Portions of this paper began as independent work by Blom (superseding relevant sections of Blom 2012) and by Cadena and Keys. First draft: September 2014.
} 


\section{Introduction}

The consequences of economic fluctuations are large and long-lasting, especially among new labor market entrants such as recent college graduates (Kahn 2010, Oreopoulos, von Wachter and Heisz 2012). In addition to immediate interruptions in employment and income, however, recessions have recently been shown to have a broad and permanent influence on household decision-making across a variety of domains.1 11 Personally experiencing economic downturns affects the formation of subsequent expectations (Malmendier and Nagel 2015), risk preferences (Malmendier and Nagel 2011), and beliefs about the role of luck in success (Giuliano and Spilimbergo 2014).

In this paper, we explore the extent to which individuals' personal exposure to economic conditions affects their investment choices. Among firms, recessions are associated with reallocations of investment toward more highly productive uses (Davis and Haltiwanger 1990, Caballero and Hammour 1994). If exposure to recessions affects expectations and risk preferences, we should observe these changes borne out in individuals allocative investment decisions as well. We focus on the decision to invest in human capital, one of the primary drivers of growth of the modern economy. There is substantial evidence that recessions affect the total amount of schooling received. In the face of a depressed labor market, potential students are more likely to continue their education and enroll in post-secondary education (Sakellaris and Spilimbergo 2000, Christian 2006, Long 2015) or graduate school (Bedard and Herman 2008).

However, recent work suggests that the allocative margin of degree field may be as important as the choice to attend or complete college at all. For example, Altonji, Blom and Meghir (2012) show that the variation in earnings across college majors is nearly as large as the average wage gap between college and high school completers. Despite the fact that this decision is as crucial a driver of earnings potential as the enrollment decision itself, we know relatively little about how students choose college majors. Prior research has creatively explored how students form expectations about a particular major's career and earnings prospects and how these expectations affect students' choices (Arcidiacono 2004, Zafar 2013) $2^{2}$ This literature, however, has largely focused on a static "point-in-time" framework or based the

\footnotetext{
${ }^{1}$ See, for instance, Ruhm (2000) on health and mortality, Currie and Schwandt (2014) on childbirth, and Hoynes, Miller and Schaller (2012) on the broader labor market impacts of recessions.

${ }^{2}$ A growing literature on major choice includes (but is not limited to) Arcidiacono, Hotz and Kang (2012), Beffy, Fougere and Maurel (2012), Betts (1996), Montmarquette, Cannings and Mahseredjian (2002), Stinebrickner and Stinebrickner (2014), Wiswall and Zafar (2015), and Zafar (2011).
} 
analysis on a single cohort, largely due to data limitations ${ }^{3}$

In this paper, we leverage new publicly available data on over 50 cohorts of college graduates to examine two specific research questions. First, does the business cycle affect the distribution of selected majors among college completers? Second, which characteristics of degree fields predict how a field's share changes with macroeconomic conditions? Previous studies have found a substantial influence of the business cycle on other facets of human capital investment including college enrollment (Betts and McFarland 1995, Hershbein 2012), college completion (Dynarski 2008, Kahn 2010), and graduate school attendance (Bedard and Herman 2008, Johnson 2013) 4 Additional research has investigated the role of economic conditions on the choice of specific careers, such as engineering (Freeman 1975) and investment banking (Oyer 2008). Yet to the best of our knowledge, this paper is the first to study the response to recession conditions by college students on the allocative margin of major choice.

We begin by outlining a framework for thinking about how students select their major. Conditional on enrollment, students choose to maximize the present discounted value of both future earnings and the non-pecuniary benefits (e.g. prestige or degree of difficulty) of a major. This general framework distinguishes among several sources of utility differences across majors, including permanent characteristics, long-run trends, short-run cyclical changes, and individual-specific preferences and skills. Our analysis of the importance of cyclical changes relies on the assumption that any changes in utility resulting from structural changes in higher education or in the labor market, discussed in detail below, are gradual enough such that they can be well approximated by flexible major-specific trends. In order to draw causal inference, we assume that, conditional on major fixed effects and these major-specific trends, the state of the business cycle when a student is choosing their college major is independent of other changes to the relative utility of college majors $5^{5}$

To answer this question empirically, we use data from the American Community Survey, which starting in 2009 collects data on field of study for all respondents with a Bachelor's

\footnotetext{
${ }^{3}$ Recent work in Chile (Hastings, Neilson and Zimmerman 2013) and Norway (Kirkebøen, Leuven and Mogstad 2014) has exploited discontinuities in centralized admissions processes to provide new estimates of plausibly exogenous returns to different fields of study and degree programs.

${ }^{4}$ See also Dellas and Sakellaris (2003) and Barr and Turner (2013) on enrollment, and Light and Strayer (2000) and Bound, Lovenheim and Turner (2009) on college completion. Charles, Hurst and Notowidigdo (2014) show that the impact of labor market conditions on educational attainment was especially pronounced during the housing boom and bust.

${ }^{5}$ The use of multiple business cycles helps to support this assumption, as long as potential changes to a particular major's relative utility are not correlated with the rise and fall of every business cycle.
} 
degree. Unlike typical data sets with information on college major, such as the NLSY or Baccalaureate and Beyond, this new data from the ACS allows us to trace out the distribution of college majors among degree-holders for more than fifty birth cohorts who experienced substantial variation in labor market conditions immediately prior to entering the workforce. This large number of cohorts facilitates the requisite flexible controls for potentially unobservable differences and differential changes in the value of each major. In addition, the large sample sizes from five waves (2009-2013) of the ACS allow us to estimate major choices at a relatively fine level of aggregation. Importantly, we are able to provide estimates separately for men and women, which is essential given their dramatically different trends in college attainment and occupational choice over the last fifty years (Turner and Bowen 1999, Goldin and Katz 2009, Gemici and Wiswall 2014).

Figure 1 presents time-series evidence that the share of college majors is starkly responsive to the business cycle. The dotted line in the figure shows the time-series from 1960 to 2011 of expected earnings for men with a Bachelor's degree who turned 20 during the reference year ${ }^{6}$ This variable is calculated as the weighted average of mid-career earnings for men with a given major, using the share of each cohort selecting a given major as weights. Importantly, the expected earnings for a given major are treated as fixed, and the average for a cohort changes only through differences in the distribution of completed majors. The solid line presents the prevailing national unemployment rate in the year that each cohort turned 20 years of age and were most likely choosing their area of study 7 The figure provides the first piece of evidence that college major choices are responsive to the business cycle, with these two series strongly co-varying (correlation coefficient $=+0.60)$.

This striking figure motivates our subsequent empirical analysis. Using de-trended multinomial logit regressions (or linear approximations thereof), we estimate how choices among 38 college major categories respond to the business cycle. Although data limitations preclude a direct analysis of the share of individuals whose choice of major changes in response to the business cycle, we find a substantial reallocation overall. Adding up the average marginal effects from a multinomial logit reveals that a one percentage point increase in the unemployment rate leads to a 3.2 percentage point total reallocation of majors for men, and a

\footnotetext{
${ }^{6}$ The average expected earnings range from $\$ 92,000$ to $\$ 96,000$ in Figure 1 because we focus on the full-time, full-year earnings of mid-career college educated males (ages 35-45), measured in 2010 dollars.

${ }^{7}$ Because we do not observe the year of graduation for degree-holders, we use the unemployment rate that prevailed at age 20, which corresponds to the second year of college for someone who graduated high school at age 18 and enrolled immediately after. This imprecision likely induces measurement error in calculating the relevant unemployment rate at the time of major selection. Thus, the responses we find are likely underestimates of the true amount of cyclical responses.
} 
4.1 percentage point reallocation for women. Scaled to a typical recession-based increase in unemployment of three percentage points, our findings suggest that recessions dramatically affect the skill content and academic specialization of cohorts.

Based on the coefficient estimates from these regressions, we investigate which majors are most affected by the business cycle. For men, the fields with the largest gains in share are engineering, accounting, business, and the natural sciences. For women, the largest gains are in nursing, accounting, and computer-related fields. In contrast, students of both genders leave fields such as sociology and education-related fields during recessions. This set of findings reveals that in the face of a tight labor market, students choose more applied fields with more relevant job training, rather than fields with broader content.

This quantification of how each major's popularity responds to changes in the unemployment rate facilitates our approach to the second research question: What (permanent) characteristics of majors are associated with a net gain or loss in "market share" of students as a result of the business cycle? Using detailed data on major-specific characteristics from the ACS and Baccalaureate and Beyond 1993 data, we investigate a number of specific hypotheses. First, we examine the degree to which students are responding to long-run (permanent income or labor force attachment) and/or short-run (e.g. finding a job more quickly) labor market prospects during recessions. We find that in response to recessions, students choose fields of study that are more challenging, require more math, and, above all, are higher paying. Both male and female students appear to be most strongly affected by median wages for prime-age workers in the occupations associated with the major, which explains 39 to 47 percent of the variation in major reallocation across the business cycle. These relationships are considerably stronger than are those with the number of job interviews or the share employed one year after completing college. For instance, majors with ten percent greater long-run median wages have a 1.8 percentage point more positive share elasticity in response to the unemployment rate for women and a 1.4 percentage point more positive share elasticity for men.

Next, we explore whether students respond to various major-specific attributes beyond labor market prospects, such as difficulty, gender balance, breadth of job opportunities, pathways to graduate school, and subsequent geographic labor mobility. We find strong support for the view that students move into more difficult fields, and this relationship continues to hold, even conditional on earnings potential. A possible explanation is that students facing weak labor markets prefer to have a stronger signal about their ability to a potential employer (Spence 1973). Similarly, women have increasing preferences for male- 
dominated, more difficult, and more career-oriented majors even conditional on long-run earnings potential. The results imply that long-run earnings prospects alone are not a "sufficient statistic" for explaining the responsiveness of major choice to economic conditions.

Finally, using our answers to these two central questions, we can quantify how substantially this compensating behavior attenuates the costs of graduating in a recession. The economic consequences of graduating in a recession are well documented, as a growing literature has shown that students suffer from the timing of their exit from school (see, e.g. Oyer (2006), Kahn (2010), and Wee (2013)). Note that the "extensive margin" compensating behaviors of increased attendance and completion of college during recessions increase the supply of college graduates competing for post-graduation employment, which likely exacerbates the negative impact of graduating in a recession (Kahn 2010, Hershbein 2012, Johnson 2013).

In contrast, students leaving fields that are most hurt during recessions and entering recession-proof fields such as engineering and nursing partially offsets the costs of graduating in a recession. Thus, the typical average estimated costs of graduating in a recession likely understate the independent effect of graduating in a lower demand environment. In other words, the impact of graduating in a recession would be even more negative if students were unable to adjust on the margin of major choice. We estimate that the offsetting labor supply response along this intensive margin is roughly one-tenth of the demand effect of graduating in a recession, or 0.6 log points of expected earnings for "recession" conditions of an unemployment rate three percentage points above average 8 Notably, the average observed wage declines due to the business cycle, therefore, represent a weighted average of earnings increases for a minority of students and large earnings declines among the remainder.

Our results extend the prior research on human capital investment, which has primarily focused on the extensive margins of whether to enroll and complete additional years of post-secondary schooling 9 This choice is a crucial one to make, as the wage gap between college and high school graduates is large (Grogger and Eide 1995, Carneiro, Heckman and Vytlacil 2011), and the completion of a college degree provides the option value for continuing on to advanced degrees (Stange 2012). Several studies have examined important elements of the broader college investment decision including credit constraints (Carneiro and Heckman

\footnotetext{
${ }^{8}$ As we discuss in more depth in the relevant section, this estimate is conservative in part because it does not adjust for variability in the impact of a recession by major, with lower earning fields hurt both more severely and more persistently than those that typically command higher wages (Oreopoulos et al. 2012, Altonji, Kahn and Speer 2013).

${ }^{9}$ See, for example, Altonji (1993) as well as Cunha, Heckman, Lochner and Masterov's (2006) discussion of the empirical literature in the context of a theoretical framework.
} 
2002, Lochner and Monge-Naranjo 2011), information barriers (Bettinger, Long, Oreopoulos and Sanbonmatsu 2012, Hoxby and Turner 2013), learning about one's ability (Stinebrickner and Stinebrickner 2012), and preferences (Cadena and Keys forthcoming). Our findings demonstrate an additional allocative margin upon which students adjust in response to labor market conditions 10

These results also have important implications beyond this specific research question. In particular, we show that women are especially responsive to changes in economic conditions in their choice of college majors. This finding extends the literature on the gender gap by showing in another setting that women are relatively more responsive to recessions and, further, suggests that this differential responsiveness may reduce the gender gap in affected cohorts (Killingsworth and Heckman 1986, Brown and Corcoran 1997, Turner and Bowen 1999, Blau and Kahn 2007, Gemici and Wiswall 2014).

Relatedly, we contribute to the literature on the determinants of STEM majors (Ehrenberg 2010, Arcidiacono, Aucejo and Hotz 2013). Especially in the case of women, we identify a latent supply of college students with sufficient ability to complete STEM fields. A rise in the unemployment rate encourages more students to pursue STEM majors, which suggests that a substantial fraction of each cohort has sufficient preparation for STEM fields, yet chooses alternative majors during periods with stronger labor market prospects. This fact suggests room for policy interventions, although further research would be needed to identify the optimal design. Finally, these findings inform the literature on career choice (Freeman 1975, Oyer 2008, Goldin and Katz 2012) by showing that not only do recessions encourage more college-going and college completion, but that graduates pursue more technical, more career-oriented, and more remunerative fields of study in response to temporary periods of weak labor demand.

The remainder of the paper is organized as follows: Section 2 provides a conceptual framework of the college major decision that directly motivates our primary empirical specification; section 3 describes the data and presents the results on cyclical changes in major choice and the correlates of majors' cyclicality; section 4 estimates how significant the bias from ignoring the reallocation of college majors during recessions is when estimating the costs of graduating in a recession; section 5 concludes.

\footnotetext{
${ }^{10}$ In some cases, parental funding of college may be tied to a student's choice of major, and a strengthening of these ties during downturns could provide a partial explanation of these changing choices. Along a different but related margin, Field (2009) and Rothstein and Rouse (2011) use experimental evidence to show that graduates are responsive to student loan debt burden in their choice of careers.
} 


\section{Conceptual Framework and Empirical Specification}

In this section we present a stylized framework of the college major decision that motivates our empirical specification. We abstract from the choice to enroll in college and instead focus solely on the choice of college major conditional on enrollment. Given our data limitations, we do not explicitly model heterogeneity or uncertainty, but we acknowledge that a richer model with these features would yield a range of interesting testable hypotheses provided a sufficiently detailed dataset.11

We begin by defining the utility of major $m$ for student $i$ in cohort $c$ to be $U_{i c m}$. In a life-cycle context, as in Altonji (1993), Arcidiacono (2004), and Altonji et al. (2012), this utility captures the present discounted value of future earnings and non-pecuniary benefits available to majors. While students gain direct utility from the costs or benefits of investment and coursework, our primary focus is on the indirect utility in a modeling sense, as majors can be mapped probabilistically into occupations with differing patterns of expected earnings, employment probabilities, breadth vs. depth of career opportunities, and other characteristics 12

Suppose we can decompose $U_{i c m}$ into fixed, structural, cyclical (which may be majorspecific), and individual components as follows:

$$
U_{i c m}=\eta_{m}+\mu_{c m}+\gamma_{c m}+\epsilon_{i c m}
$$

The fixed component of the utility "return" to a major, $\eta_{m}$ captures all of the fixed (across cohorts) components of the major's potential employment and wage opportunities, as well as non-pecuniary costs and benefits, over the life-cycle. For example, a degree in Engineering has always required more math-intensive coursework and has always led to a more specific set of career options as compared to a degree in Sociology. Over the time period of our study (cohorts turning 20 from 1960-2010), a number of "structural" $\left(\mu_{c m}\right)$ factors have also altered the relative utility of different majors. For example, in more recent cohorts, women have faced fewer barriers to completing traditionally "male" majors, which increases the relative utility of pursuing those types of degrees. Note that without further assumptions, it is not possible to separately identify the influence of structural changes versus cyclical

\footnotetext{
${ }^{11}$ Previous research has often used assumptions regarding rational expectations (see, e.g. Berger (1988)), or myopic expectations (as in Freeman (1975)) about the path of future wages, which depend on both the actual degree of wage persistence as well as the degree of information constraints facing students. See Zafar (2011) and Arcidiacono et al. (2012) on how college students actually form these expectations.

${ }^{12}$ See the relevant extended discussions in Beffy et al. (2012) and Montmarquette et al. (2002).
} 
changes because both operate at the cohort $\times$ major level.

In what follows, our key assumption is that any changes in utility resulting from these types of structural components occur gradually over time, and thus can be represented by a major-specific, sufficiently smooth, function of time (birth cohort), $\mu_{c m}=f_{m}(c)$. In other words, any long-run structural characteristics of a major must change gradually rather than abruptly changing over a business cycle. Empirically, we will operationalize this assumption by including both major fixed effects and flexible major-specific trends to account for unobservable characteristics of majors that are either permanent or smoothly time-varying. Including these controls in specifications run separately for men and women allows us to remove the influence of substantial differences in trends for men and women over this time period (Gemici and Wiswall 2014).

The cyclical component, $\gamma_{c m}$, reflects the fact that certain majors fare differently over the business cycle, including through earnings or employment effects of the recession itself. To begin, we ask whether the unemployment rate has any effect on the distribution of selected majors. This allows us to estimate the effect of the unemployment rate semi-parametrically rather than as a function of major characteristics. In practice, we allow for the utility of the major to depend on $\beta_{m} * u n e m p_{c}$. The only restriction here is one of linearity, i.e. that the major-specific effect of the unemployment rate (at age 20) on the utility of each major is linear with respect to the unemployment rate.

Re-writing equation (1) to include these assumptions provides the initial basis for a functional form:

$$
U_{i c m}=\beta_{m} * u n e m p_{c}+\eta_{m}+f_{m}(c)+\epsilon_{i c m}
$$

The student chooses major $m^{*}$ such that $U_{i c m^{*}} \geq U_{i c m} \forall m \neq m^{*}$. Note that because the unemployment rate is a cohort level characteristic, we should not run conditional logit models without correcting for the correlation in the error terms. In fact, in our main specifications we instead aggregate to cohort-major cells and run linear regressions based on the functional form suggested by this model. To reach our main empirical specification, consider how the observed population shares in a given cohort-major $\left(S_{c m}\right)$ will depend on the choice probability $\left(\operatorname{Pr}\left(m=m^{*}\right) \equiv \pi_{c m}\right)$ plus an error term.

$$
S_{c m}=\pi_{c m}+\nu_{c m}
$$

Assuming $\epsilon_{i c m}$ is independent across majors and has a Type I extreme value distribution, we can expand the above equation to: 


$$
S_{c m}=\frac{e^{\beta_{m} * \text { unemp }_{c}+\eta_{m}+f_{m}(c)}}{\sum_{M} e^{\beta_{m} * u n e m p_{c}+\eta_{m}+f_{m}(c)}}+\nu_{c m} .
$$

The denominator of the $\pi_{c m}$ portion is a constant (within cohort), so for simplicity we denote it as $e^{-\gamma_{c}}$.

$$
\operatorname{Pr}\left(m=m^{*}\right)=e^{\beta_{m} * u n e m p_{c}+\eta_{m}+f_{m}(c)+\gamma_{c}}+\nu_{c m}
$$

Taking logs and linearizing around $\nu_{c m}=0$ yields:

$$
\log \left(S_{c m}\right) \approx \beta_{m} * \operatorname{unemp}_{c}+\eta_{m}+f_{m}(c)+\gamma_{c}+\frac{\nu_{c m}}{\pi_{c m}}
$$

Empirically, we approximate $f_{m}(c)=\delta_{1 m} c+\delta_{2 m} c^{2}$, which combined with the major fixed effects allows for a rich set of unobservables to affect majors' relative shares in each cohort. In addition, we bootstrap the standard errors to account for heteroskedasticity (due to the influence of $\pi$ ) and the non-independence of the error terms within cohort. The relatively long time dimension of the panel supports this method of conducting inference, which is important because the cohort level is the effective level of variation.

A semi-elasticity regression specification such as this one faces the challenge that we cannot separately identify $\gamma_{c}$ and all of the $\beta_{m}$ coefficients on unemp $p_{c}$. We address this issue by assuming that all of the $\gamma_{c}$ are zero for each $c$. In effect, this assumption implies that the unemployment rate does not alter the average $\log$ (share) across all majors. Briefly, this assumption allows us to avoid choosing a reference major to compare our results to, and it keeps our specification more easily interpretable than a multinomial logit specification, which would directly impose an adding up constraint. In the Appendix we discuss a test for assessing the validity of this assumption (which the data fail to reject), as well as robustness results using average marginal effects from a multinomial logit specification, and our semielasticity approach yields extremely similar results both qualitatively and quantitatively.

Finally, a note on causality. In order to draw causal inference, we must assume that, conditional on the major fixed effects and major-specific quadratic trends, the state of the business cycle when a student is choosing her college major is independent of other changes to the relative utility of college majors. Given that reverse causality is infeasible (students' choices of college major do not determine the national unemployment rate), and that overall trends in major shares appear to be fairly smooth, we believe this to be a reasonable assumption. Note that we do not need to know the mechanism by which unemployment affects 
major choice to establish causality. In fact, we would need stronger assumptions (i.e. an exclusion restriction) to determine the effect of potential mechanisms through which cycles could affect major choices, e.g. earnings or employment expectations. Thus, we think of our approach as treating recessions as natural experiments, and determining the extent to which recessions, exogenous from the perspective of contemporaneously enrolled college students, lead to changes in the composition of college majors.

\section{Data and Results}

\subsection{Data Sources and Descriptives}

Our empirical analysis takes advantage of field-of-study questions available beginning in the 2009 wave of the American Community Survey 13 All respondents in this roughly one percent cross-sectional sample of the U.S. with a bachelor's degree or higher were asked to report the field of study for their bachelor's degree. By combining data from the five annual surveys from 2009-2013, we are able to calculate the distribution of college majors for cohorts turning age 20 from 1960-2011 based on a roughly five percent random sample of the population. The ACS also includes the respondent's age, which allows us to add age-specific unemployment rates to each record ${ }^{14}$ The initial analysis uses this data source to determine whether and how major choices change over the business cycle.

We then supplement these cyclicality estimates with characteristics of majors calculated from the public use version of a single wave (1993) of the Baccalaureate and Beyond survey $(\mathrm{B} \& \mathrm{~B}){ }^{15}$ In order to combine these two data sources, it was necessary to create a standardized list of majors that can be constructed from the underlying coding schemes in both surveys. We created this list of majors by hand, with the goal of making the aggregate major categories as coherent as possible between the two surveys. Appendix Table A-2 provides more detail on the construction of the 38 major categories used in the analysis.

\footnotetext{
${ }^{13}$ We accessed the ACS through the IPUMS web server (Ruggles, Alexander, Genadek, Goeken, Schroeder and Sobek 2010).

${ }^{14}$ We use the annual national unemployment rate, calculated among all persons ages 16 and over: BLS series ID LNU04000000.

${ }^{15} \mathrm{We}$ accessed these statistics using the PowerStats portal, which is accessible via http://nces.ed.gov/datalab/. We created a customized version of the MAJCODE1 variable that grouped fields according to the categories provided in Appendix Table A-2.
} 


\subsection{Cyclical Changes in Major Choices}

\subsubsection{Specification and Identifying Variation}

We first explore whether there is a systematic relationship between the prevailing unemployment rate when a birth cohort reaches age 20 and the distribution of college majors selected among that cohort's college graduates. In the results below, we estimate a linear regression model with major $(m) \times$ birth cohort $(c)$ cells as observations, which is motivated by the discussion in the previous section ${ }^{16}$ We use the 38 major classifications discussed previously and the 52 birth cohorts that turned 20 years old in the years 1960-2011. All of the analysis is run separately for men and women.

$$
y_{m c}=\beta_{m} * \text { unemp } 200_{c}+\eta_{m}+\delta_{1 m} * c+\delta_{2 m} * c^{2}+\epsilon_{m c}
$$

In our primary specification, we estimate Equation 7 using the natural $\log$ of the major's share within each cohort as the dependent variable. Note that this specification contains a coefficient on the unemployment rate for each major, $\beta_{m}$, controlling for major-specific fixed effects $\left(\eta_{m}\right)$ and major-specific quadratic trends ${ }^{17}$ We report standard errors based on a block-bootstrap procedure that resamples entire cohorts $\sqrt{18}$ We also save each of these bootstrap trials for use in subsequent analysis.

The specification thus leverages cyclical deviations in major share relative to long-run trends. This approach requires an exceptionally long panel of college majors, which the ACS uniquely provides, in order to flexibly estimate major-specific trends. In the main text, we rely on major-specific quadratic trends, but Appendix Section A-1 explores the robustness of this choice to a variety of parametric and nonparametric alternatives. Figure 2, which corresponds to the analysis for women, provides examples of the identifying variation isolated by this approach. Panel A shows both the raw $\log$ (share) data (the solid line) and the fitted quadratic trends (the dashed line) for Engineering and for Early and Elementary Education from 1960-2011. As each of these fields experienced substantial changes in share over this time period, the importance of controlling for long-run trends is readily apparent in the figure.

\footnotetext{
${ }^{16}$ Nevertheless, we have estimated the corresponding conditional logit model for robustness, and we include a comparison of the resulting estimates in Appendix Figure A-1. In practice, the choice of methodology has little influence on the substantive conclusions, as the average marginal effects from the conditional logit are very similar to the linear regression estimates.

${ }^{17}$ For a detailed examination of the determinants of these long-run trends, see Gemici and Wiswall (2014).

${ }^{18}$ We used 5000 bootstrap trials, and the results of this procedure produce qualitatively similar standard errors compared to using cluster robust standard errors clustered at the cohort level.
} 
The solid lines in Panel B of the figure show the residual changes in $\log$ (share) after removing the influence of these major-specific trends. The dashed lines represent a similarly de-trended version of the unemployment rate 19 The figure shows that the share of women choosing these two types of majors responds quite differently over the business cycle. The share choosing Engineering is strongly pro-cyclical while the share choosing Early and Elementary Education is strongly countercyclical. The estimated coefficients are +0.13 for Engineering and -0.062 for Early and Elementary Education, which implies that each percentage point increase in the unemployment rate increases the share of women choosing Engineering by roughly thirteen percent and decreases the share of women choosing Early and Elementary Education by a little more than six percent.

\subsubsection{Major Cyclicality Results}

Figure 3 provides analogous coefficient estimates of the cyclicality of each of the 38 major categories among women. In general, the results are in line with the results from Figure 1, as majors associated with higher salaries tend to gain share while majors associated with lower salaries tend to lose share in response to a one percentage point increase in the unemployment rate. There is also a substantial overall shift in the distribution of major choices over the business cycle: 22 of the 38 majors have an unemployment gradient that is statistically significant at the 0.01 level, and an additional five majors have coefficients that are different from zero at either the 0.05 or 0.10 level.

Note that these coefficient estimates are semi-elasticities, and thus that some of the larger percentage changes are due in part to small baseline probabilities. Figure 4 provides corresponding coefficient estimates of Equation 7 using the raw share values as the dependent variable. This alternative specification shows that, in raw selection probability terms, the greatest gain in share occurs in Business fields: A one percentage point increase in the unemployment rate leads to more than a 0.6 percentage point increase in the share of women graduates with business degrees. Similarly, a one percentage point increase in the unemployment rate decreases the share of women with any education degree by more than one percentage point (combining the coefficients on the two education fields).

The results for men are broadly similar, with most majors either gaining or losing share consistently across both gender groups ${ }^{20}$ The semi-elasticity results for men are given in

\footnotetext{
${ }^{19}$ Specifically, this line shows the residuals from a regression of the unemployment rate on a quadratic trend fit over the same time period.

${ }^{20}$ Although the point estimates differ in sign for a few majors, there is no category for which both of these
} 
Figure 5 and share estimates are in Figure 6. Appendix Table A-3 contains a complete set of numerical results, including standard errors for the coefficient estimates and the long-run average shares for each major separately by gender. There are, however, smaller changes overall among men's chosen field in response to fluctuations in the unemployment rate. Adding up the absolute value of the coefficients for shares yields 4.1 percentage points in total reallocation among women as opposed to 3.2 percentage points among men ${ }^{21}$ The stronger response among women along this margin is consistent with women having more elastic labor supply generally (Killingsworth and Heckman 1986, Heckman 1993, Blau and Kahn 2007). Overall, the evidence from these figures suggests that the business cycle has a substantial impact on the distribution of college majors, with a notable shift toward degrees that tend to pay higher salaries.

\subsection{Correlates of Majors' Cyclicality}

The goal of this section is to characterize the time-invariant attributes of college majors that are associated with the major's cyclicality. Put simply, what characteristics of majors attract more students in a recession? We explore this question using major attributes as measured in the ACS and in the 1993 Baccalaureate and Beyond (B\&B) survey. Note that this set of specifications is cross-sectional, and we in effect assume that the relative differences in major characteristics are fixed over time. Although this assumption does not need to be strictly true, it must be plausible that students' perceptions of the relative rank ordering of majors does not change substantially over our period of analysis. We divide the set of available major characteristics into four groups: long run labor market characteristics, short run labor market characteristics, degree of difficulty, and other attributes ${ }^{22}$ This division is useful for exploring a range of hypotheses surrounding why certain college majors exhibit greater cyclicality than others.

point estimates are statistically significantly different from zero. Appendix Table A-4 shows the difference in coefficients, including tests of the differences in elasticities between genders.

${ }^{21}$ The level of these estimated net reallocation effects is naturally sensitive to the number of major categories. Narrower classifications of major categories would naturally increase these estimates as long as there is some switching happening within these relatively broad categories. Our 38 major groupings combine fields in some cases, and thus do not allow for a switch from majoring in English to majoring in a foreign language to be classified as a reallocation, for example.

${ }^{22}$ Summary statistics for each of these variables is available in Appendix Table A-5. 


\subsubsection{Bivariate Relationships with Major Cyclicality}

We begin with a set of bivariate regressions using the semi-elasticity coefficients on the unemployment rate from Equation 7 as the dependent variable and a number of major characteristics as explanatory variables:

$$
\hat{\beta}_{m}=\phi_{0}+\phi_{1} * X_{m}+\omega_{m}
$$

As the dependent variable in this second-stage regression is derived from the earlier "first-stage" analysis, we do not estimate equation 8 by OLS. Instead we make two adjustments. First, we weight each observation by the inverse of the estimated variance of the $\beta_{m}$ term, which we calculate using the bootstrap trial estimates of the $\beta$ 's from the first stage ${ }^{23}$ Second, in order to conduct inference, we empirically approximate the distribution of the second-stage coefficients ( $\phi$ 's) by estimating equation 8 repeatedly using the set of $\beta$ coefficients from each of the first-stage bootstrap trials. We report standard errors calculated as the standard deviation of the relevant $\phi$ coefficient from this distribution ${ }^{24}$

We first analyze the relationship between cyclical changes in share and the long-run earnings of a major. Figure 7 presents this relationship for women with median wages of prime-age workers on the x-axis and the degree of cyclicality (as estimated above) on the yaxis. Each dot represents a major, and the figure shows a strong positive relationship between average "long-run" wages and the fields that are most responsive to the business cycle, with more female students entering higher-paying fields (such as Pharmacy and Engineering) when unemployment rises. Recall that the cyclicality measures are within-major changes in market share due to higher unemployment, conditional on slow-changing trends. Thus, the results in Figure 7 imply that students behave as though the utility of selecting a major with higher long-run earnings increases during a recession.

There are two likely explanations for this phenomenon. Perhaps the most obvious candidate is the heterogeneity in earnings losses experienced by those who graduate in a recession based on their chosen major (Oreopoulos et al. 2012). As shown by Altonji et al. (2013), this heterogeneity is primarily a function of the long-run earnings associated with each major.

\footnotetext{
${ }^{23}$ The choice to weight has relatively little impact on the coefficients, although the coefficient estimates are more stable across specifications that include different numbers of major categories (for example, due to data not being available from B\&B).

${ }^{24}$ The standard errors from this method, which takes into account the non-independence of the estimated $\hat{\beta_{m}}$ 's, are substantially smaller than OLS standard errors that assume independence. This difference reflects the fact that the two-step procedure produces results that are identified from variation at the cohort-major level in $u n e m p_{c} \times X_{m}$ rather than from variation at the major level alone.
} 
Graduates who choose majors with lower long-run earnings lose, on average, more of their lifetime income when they graduate in a high unemployment environment. Thus, part of this relationship likely results from students' responses to these differential anticipated losses in earnings.

In addition, the experience of graduating in a time of high unemployment may alter how students collect and consider information about the relative returns to majors. Although students typically have fairly imprecise information about the relative value of different degrees, they may optimally choose to pursue this information during a time of labor market distress. This type of more intensive information gathering could also serve to increase the relative utility of majors that lead to higher salaries as students' priors become less diffuse. Each of these reasons, therefore, is consistent with the observed re-balancing of the major distribution toward those that tend to have higher earnings.

The corresponding slope coefficient from Figure 7 is presented formally in the first row and first column of Table 1. This statistically significant coefficient implies that each ten percent increase in long-run median wages leads to a $1.9 \mathrm{log}$ point more positive semi-elasticity with respect to a one percentage point increase in the unemployment rate. For example, Nursing majors earn about twenty percent more than Psychology majors. Majors whose graduates earn in the range of Nursing are expected to see gains in share of roughly 3.3 percent with each one percentage point increase in the unemployment rate. In contrast, majors that pay like Psychology are expected to lose 0.5 percent share with each percentage point rise in unemployment.

Each of the additional entries in Table 1 provides the corresponding coefficient from a similar bivariate regression with the same dependent variable (the major-specific coefficients on the unemployment rate) and alternative explanatory variables. The relationship between major cyclicality and the share of majors working full-time, full-year is shown in row 2 . Again, there is a statistically strong, positive relationship between changes in major share during times of high unemployment and the long-run labor market prospects of a major. Taken together with the results in the first row, the results reveal that, despite the fact that most recessions are relatively short-lived, students of both genders make permanent investments in fields of study with more favorable long-run labor market potential when the macroeconomy is relatively weak.

The next sets of results in Table 1 examine the relationship between the cyclical changes in major shares and the short-term benefits and short-term costs associated with each major. Recall that these are intended to be "typical" short-run characteristics of the majors, 
calculated from a single cross-section, and thus reflect a changing prioritization of these characteristics rather than a response to cyclical changes in the characteristics themselves. We find that both men and women choose majors with higher employment rates one year after graduation, more job interviews, and a higher share of jobs in related fields. Thus, recessions increase the importance that students place on being able to find employment in a related field relatively soon after graduation.

Perhaps relatedly, the results in the third panel on major difficulty suggest that students are willing to exert more effort during school by selecting more challenging majors during recessions. Majors with the most mathematical rigor and least grade inflation (such as Engineering) are most responsive to the business cycle, a pattern that holds for both men and for women. Thus, recessions appear to alter students' willingness to pay short-term costs of additional difficulty and effort while in school to obtain majors with these advantages.

Finally, the last panel of Table 1 explores a number of alternative hypotheses. First, we find that students avoid majors with a high share of women (such as Sociology) during recessions. This pattern holds for both male and female students. This finding is of particular interest for female students given concerns that women likely face barriers to pursuing degrees in male-dominated areas, such as STEM fields 25

The fact that women are more likely to choose gender-atypical majors during a recession has important implications for policymakers seeking to alter women's participation in these fields. First, these results are consistent with earlier findings that there is a sizable share of women whose academic preparation and ability allow them to complete either a more quantitative major or a more gender-typical major (Turner and Bowen 1999, Goldin 2013). Additionally, the fact that women are more likely to choose these majors in a recession provides some insight into what types of policy interventions may prove effective in encouraging women to pursue male-dominated fields. Perhaps better information about the relative career prospects or programs designed to encourage women to think of college as an "investment" rather than as "consumption" may be particularly effective. Although we are unable to disentangle the potential mechanisms, it is clear that some aspect of the high unemployment environment effectively encourages women to enter gender-atypical fields. Notably, this type of exogenous increase in female representation in male-dominated fields may have spillover encouragement effects on subsequent cohorts depending on the nature of the barriers women face in entering those fields (Goldin 2014).

\footnotetext{
${ }^{25}$ Ehrenberg (2010) provides an overview of these concerns, and additional articles in the same issue address specific research questions related to the differential persistence across gender in STEM fields.
} 
In addition, we consider whether high unemployment encourages students to prefer majors that allow for greater career mobility, either across geographic labor markets or across occupations. These options could provide an additional hedge against the risk of graduating in a recession. In the next row of the last panel in Table 1, we find that women are drawn to more geographically mobile majors during recessions, unconditional on labor market prospects (we present multivariate analysis below). Despite the fact that college completion has been shown to causally increase geographic mobility (Malamud and Wozniak 2012), perhaps surprisingly this mobility does not differentially increase during recessions for men. We also find no evidence that male students differentially select majors that provide more potential occupations, as we observe no relationship between major cyclicality and a measure of occupational concentration in that major (based on a Herfindahl-Hirschman Index), while women move into majors with less concentrated occupation options and thus more general sets of skills 26

Similarly, we find that students tend to move away from majors that typically lead to graduate school. The final row of the table shows negative point estimates for both men and women, although the coefficient is three times larger for women than men. These estimates suggest that recessions lead to more students choosing majors that are effectively "terminal," i.e. that lead to careers without additional schooling. This perhaps surprising result implies that, although some students "wait out" recessions by attending graduate school (Johnson 2013), this behavior likely does not reflect a forward-looking choice of an undergraduate major that more often leads to graduate school. In sum, we find robust evidence that recessions alter the distribution of completed college majors toward those that have higher labor market returns. Students are more likely to select higher-paying jobs with better long-term employment rates and a higher likelihood of working in a related field relatively soon after graduation.

\subsubsection{Multivariate Relationships with Major Cyclicality}

In the standard life-cycle model of college major choice (as in Berger (1988)), students' major decisions should respond exclusively to long-run earnings prospects, assuming fully forward looking agents with exponentially discounted time preferences. There is, however, scope for recessions to alter students' choices beyond the effects of a widening gap in expected earnings. In particular, students may experience an incentive to increase their information

\footnotetext{
${ }^{26}$ This potentially counter-intuitive result is driven by movements out of Early and Elementary Education, the second most concentrated major (after Pharmacy majors).
} 
gathering from typically low levels and to pay closer attention to the differences in career prospects afforded by different majors. Additionally, recessions may increase the value of higher education as a signaling device (Spence 1973), and more difficult majors may gain in market share, even beyond what would be expected given their long-run earnings. In the next set of results, therefore, we run "horse race" regressions to test whether other major characteristics are related to the cyclicality of college majors, conditional on how the recession alters relative long-run wage prospects. Recall from the previous discussion that heterogeneity in earnings losses as a result of recessions derives primarily from the long-run earnings and employment probabilities of a graduate's major.

Table 2 presents the multivariate results related to labor market prospects for women (columns 1-3) and men (columns 4-6), respectively. Beginning in column 1 of Table 2 , it is clear that long-run earnings are quite predictive of cyclical changes in share among women: this single variable explains nearly half of the variation (47.4\%) in majors' cyclicality. The ability to find employment, and to find related employment in particular, are strong independent predictors of cyclical changes in share as well (columns 2 and 3). Each of these variables likely reflects students choosing majors with relatively smaller recession-induced declines in labor market prospects. These four measures of labor market prospects explain over three-quarters of the overall variation in majors' cyclicality.

Columns 4-6 of Table 2 show parallel results for men. Again, long-run earnings explain a significant portion (39\%) of the variation in majors' cyclicality. The ability to find employment within the first year is an especially large and significant correlate of cyclicality for men. Our available measures of long- and short-run earnings prospects and employment probabilities explain nearly $60 \%$ of the overall variation in major cyclicality for men.

In Table 3, we show the relationships between major attributes and major cyclicality conditional on labor market prospects (the four variables shown in Table 2 ) for women and men, respectively. This table tests whether any of the previously discussed correlations (shown above in Table 1 remain after controlling for changes in relative labor market returns. Notably, we find that, even conditional on changes in earnings, recessions induce women to choose gender-atypical fields. Women also choose more difficult majors during recessions, even controlling for the fact that more difficult majors typically experience smaller declines in expected earnings. Furthermore, women are more likely to select a major with a career orientation, i.e. one with a greater likelihood of working full time during prime earnings years. Thus, it is not simply that cyclical majors with higher earnings also happen to be male-dominated, more difficult, and more career oriented, but rather that women have 
increasing preferences for each of these features conditional on long-run earnings potential.

Men generally exhibit similar patterns of major cyclicality, but the magnitudes of the responsiveness (relative to women) are frequently of smaller magnitude. Men similarly choose more difficult majors during recessions, majors with a greater likelihood of working full time, and majors that are more male-dominated. These findings support the view that long-run earnings prospects alone are not a sufficient statistic for understanding the responsiveness of either men's and women's major choices to economic conditions, as we observe relationships that are consistent with increased information gathering as well as the increased value of education as a signaling device during recessions.

\section{Implications for the Analysis of Graduating in a Re- cession}

The previous section established that students respond to increases in the unemployment rate by selecting more difficult majors that command higher earnings levels in the labor market. However, to our knowledge, no empirical analyses of the earnings losses of graduating in a recession incorporate the impact of this compensating behavior. In this subsection, we discuss one approach to estimating the magnitude of the omitted variable bias from failing to consider the major-reallocation response to recessions. To fix ideas, consider the following analytical framework:

Suppose that the earnings of a cohort shortly following a recession, $\log (\text { earnings })_{c}$, are a function of demand conditions at graduation (unempgrad) and the average market value of the cohort's selected majors (majorval):

$$
\log (\text { earnings })_{c}=\beta_{0}+\beta_{1} \text { unempgrad }_{c}+\beta_{2} \text { majorval }_{c}+\epsilon_{c}
$$

Assume that when both the unemployment rate and the value of the major are included in a regression model that the coefficient on unempgrad $_{c}$ is the causal effect of the unemployment rate on $\log ($ earnings $){ }^{27}$ Previous analysis, instead, estimates the relationship between the earnings of a cohort and the unemployment rate in the context of a "short" regression

\footnotetext{
${ }^{27}$ For simplicity, we discuss this regression without controls. It is straightforward to generalize this specification to one that includes a number of additional controls and to treat these three variables and the residual as having been purged of the influence of those controls. In this case, this assumption would be conditional on these controls.
} 
without the control:

$$
\log (\text { earnings })_{c}=\tilde{\beta}_{0}+\tilde{\beta}_{1} \text { unempgrad }_{c}+\tilde{\epsilon}_{c}
$$

with the standard omitted variable bias to $\beta_{1}$ :

$$
\tilde{\beta}_{1}=\beta_{1}+\beta_{2} \frac{\operatorname{Cov}(\text { majorval }, \text { unempgrad })}{\operatorname{Var}(\text { unempgrad })}
$$

Now suppose further that the unemployment rate at graduation does not directly affect the distribution of chosen majors (because it is too late to make adjustments), but that it is correlated with the unemployment rate midway through one's academic career, which does influence the set of majors selected by a cohort:

$$
\text { majorval }_{c}=\gamma_{0}+\gamma_{1} \text { unempmid }_{c}+\eta_{c}
$$

Again, relying on the assumption that the unemployment rate at graduation is unrelated to the residual in the major value equation, the omitted variable bias expression in (11) simplifies to:

$$
\tilde{\beta}_{1}=\beta_{1}+\beta_{2} \gamma_{1} \delta_{1}
$$

with $\delta_{1}=\frac{\text { Cov(unempmid,unempgrad })}{\operatorname{Var}(\text { unempgrad })}$.

Therefore, the coefficient on the unemployment rate at graduation will be biased when omitting the composition of majors as long as the product $\beta_{2} \gamma_{1} \delta_{1}$ is not zero. The numerical value of the bias depends on slope coefficients from three regressions: [1] The "long" regression coefficient of earnings on major value $\left(\beta_{2}\right)$, [2] A regression of major value on the unemployment rate midway through school $\left(\gamma_{1}\right)$, and [3] A regression of the unemployment rate midway through school on the unemployment rate at graduation $\left(\delta_{1}\right)$.

We expect that the first coefficient, $\beta_{2}$, is positive by construction - more valuable majors increase earnings. As the previous results in the paper have shown (including perhaps most directly Figure 11), the sign of $\gamma_{1}$ is also positive, as the typical major-based earnings capacity of a cohort rises in response to unemployment experienced partway through school. The final coefficient, $\delta_{1}$, is also positive: A regression of the unemployment rate at time $t$ on the unemployment rate at time $t+2$ over our time period yields a coefficient of +0.43 .28$ Thus, the total omitted variable bias is positive: The typical estimate of the negative effect of graduating in a recession is, in fact, an underestimate of the earnings losses due to weak

\footnotetext{
${ }^{28}$ This specification is run using data from 1960-2012, and it includes the same quadratic trends used in the main analysis.
} 
demand at graduation.

\subsection{Quantifying the Bias}

Quantifying the magnitude of this bias requires numerical estimates of the first and second regression coefficients in addition to the +0.43 estimate of $\delta_{1}$. Doing so requires a more exact definition of majorval. In the analysis that follows, we calculate majorval for each cohort as the weighted average of the median mid-career (ages 35-45) $\log$ (earnings) associated with the distribution of majors selected by that cohort. Importantly, we treat the earnings potential of majors as constant across cohorts, but the weights on each major, $\pi_{j c}$, change from cohort to cohort.

Consider two cohorts that experience different levels of unemployment during college. We can write the difference in the average of any permanent major characteristic $(\bar{x})$ across cohorts 0 and 1 as

$$
\overline{x_{1}}-\overline{x_{0}}=\sum_{j}\left(\pi_{j 1}-\pi_{j 0}\right) x_{j} .
$$

Evaluating this expression is straightforward given our estimates of how the shares of each major change with unemployment and a measure of mid-career earnings for each major. Specifically, suppose that cohort 0 faces average unemployment levels and cohort 1 faces unemployment that is 1 percentage point higher. Based on our earlier results, we can calculate the difference in share for each major as as $\pi_{j 1}-\pi_{j 0}=\left(e^{\beta_{j}^{\text {unemp }}}-1\right) \cdot \pi_{j}^{0}$, and then multiply each difference in major share by that major's long-run earnings, $\bar{x} 29$

Taking the weighted sum of the changes in shares across all 38 majors yields approximately $+0.5 \log$ points. In other words, the increase in permanent earnings capacity of a cohort rises by roughly 0.5 percent with each percentage point increase in the unemployment rate it experiences at age 20 as a result of the resulting change in the distribution of chosen majors 30 To obtain the effect of an increase in unemployment at the time of graduation, we scale this coefficient by 0.43 , the increase in unemployment at age 20 associated with a one percentage point rise in the unemployment rate at age $22\left(\delta_{1}\right)$. This adjustment reflects

\footnotetext{
${ }^{29}$ Alternatively, we could use the results of the share level regressions, which would take the more straightforward form: $\pi_{j 1}-\pi_{j 0}=\beta_{j}^{u n e m p}$. In practice, this choice turns out to be immaterial because the results are so similar to each other.

${ }^{30}$ The weighted change in $\log$ (median earnings) with each one percentage point increase in the unemployment rate is 0.49 for men and 0.5 for women. In implementing these calculations, we adjust the changes in share to sum to zero across all majors, which is not required in the log(share) specification. We subtract from each major's change in share a portion of the total change in share that is proportional to the absolute value of the unadjusted change in share, requiring the resulting coefficients sum to zero.
} 
the fact that economic conditions at the time of major choice are correlated with but not identical to those faced at the time of graduation. Thus, a cohort graduating in a recession (with unemployment three percentage points higher than average) can be expected to have major-based earnings capacity that is $0.5 * 0.43 * 3 \approx 0.64 \log$ points higher than the cohort graduating with average unemployment 31

The only remaining component of the calculation is selecting a reasonable value of $\beta_{2}$, the regression coefficient of earnings in a recession on major value. Given that both the omitted variable and the dependent variable are measured as $\log$ (earnings), a reasonable benchmark is $\beta_{2}=1$. A coefficient of 1 would imply that the relative differences in earnings across majors in the years following graduation would be equal in percentage terms to those in mid-career. Imposing this value likely results in a conservative bias calculation, given that recessions tend to expand the earnings gaps between high-paying and low-paying majors (Oreopoulos et al. 2012, Altonji et al. 2013).

These calculations thus imply that an analysis that treats the major distribution as fixed will have a positive bias of roughly $0.64 \mathrm{log}$ points. Compared to typical estimates in the -6 to $-8 \log$ point range, e.g. (Kahn 2010), this bias is not insignificant, but it does imply that labor demand conditions have an even stronger adverse effect on young graduates than previously estimated. Our results imply that the demand effect alone is roughly ten percent larger than the combined effect of supply and demand. Thus, even accounting for recessioninduced changes to college majors, it seems likely that most students who graduate during a recession experience negative earnings as a result.

In contrast, the results suggest relatively mild earnings effects from experiencing a recession while in school. For example, our results imply that a 3 percentage point rise in unemployment rates at age 20 leads to a distribution of majors that earns roughly 1.5 percent more, on average, on a permanent basis. Because we cannot observe both the chosen and counterfactual major, we are unable to determine for any particular individual how a recession affects her lifetime earnings ${ }^{32}$ Nevertheless, it seems likely that for many students, the presence of a recession does not alter their chosen major. In this case, the estimated increase of 1.5 percent of earnings on average reflects substantial heterogeneity between marginal and inframarginal individuals. Among those who switch majors as a result of the recession, the recession induces a large increase in lifetime earnings, even when accounting

\footnotetext{
${ }^{31}$ This characterization of a "recession" is the same as used in Altonji et al. (2013).

${ }^{32}$ In addition, this is an inherently partial equilibrium estimate, and there may be broader general equilibrium effects, as found in Bianchi's (2014) study of Italian educational reforms.
} 
for the negative labor demand effect at the time of graduation.

For example, suppose that fifteen percent of the population switches majors in response to a recession, in line with our estimate for net switching among female students. In that case, those fifteen percent would see a nine percent increase in lifetime earnings capacity, while the other 85 percent are unchanged. Even if fully 30 percent of the population switches, the average gains among switchers would be larger than the resulting demand shock ${ }^{33}$ Thus, many students who face high unemployment during and immediately after college actually experience an increase in lifetime earnings because the recession changes their investment in human capital through the allocative margin of major choice.

\section{Conclusion}

Personal experience with transitory economic downturns shapes individuals' preferences and expectations in surprisingly long-lasting ways. In this paper, we take advantage of the release of unprecedented data on degree recipients in the United States to investigate the impact of economic conditions on the choice of college major, a central component of "permanent" human capital. Using data on college major choice from the American Community Survey for cohorts graduating between 1962 and 2013, we show that the distribution of college majors changes substantially in response to the business cycle. The sample size and long time dimension of our dataset allow us to control comprehensively for fixed and slow-moving structural changes to the demand for and components of college majors over this fifty year period. We estimate that a one percentage point increase in the unemployment rate leads to a 3.2 percentage point total reallocation of majors for men, and a 4.1 percentage point reallocation for women.

The recession-induced reallocation in college majors shifts the distribution toward fields of study that are more challenging, require more math, and, above all, are higher paying. Longrun earnings in a given major is the strongest predictor of recession-induced reallocation into the field, explaining more than one-third of the variation in cyclical elasticities. Nonetheless, even conditional on long-run earnings we show that students move into more difficult, more male-dominated (among women), and more career-oriented fields. These shifts suggest that a substantial number of college students make an (short- and long-run) earnings-maximizing

\footnotetext{
${ }^{33}$ Note that each percentage point increase in the unemployment rate at age 20 corresponds with a roughly 0.5 percentage point increase in the unemployment rate at age 22 . Thus, the earnings decline due to graduating with high unemployment for this cohort would be roughly half of the six to eight percent losses in the literature.
} 
response to recession conditions by choosing majors that are more insulated from recessions.

We also find that recessions lead to share increases among more difficult and maledominated majors, even controlling for differences in earnings and the likelihood of finding employment. These additional results suggest that in response to anticipated weak labor demand upon graduation, students either devote more resources to learning about the career potential of majors or become more sensitive to the signal that their major sends about their ability to potential employers. The stark responsiveness to the business cycle suggests that many college students, and especially female college students, have sufficient ability to complete more challenging majors, such as STEM fields, yet choose not to do so in periods with stronger labor market prospects ${ }^{34}$ A direction for future research is to understand what aspects of the business cycle lead to this adjustment and whether it is possible to encourage greater take-up of these more difficult fields even in a healthy labor market.

Finally, we use our findings to estimate the bias from estimating the impact of graduating in a recession without accounting for the endogenous changes in the distribution of college majors. Relative to the estimated impact of graduating in a recession on the order of 6 percent, we find that this coefficient is biased downwards by roughly ten percent. In other words, the offsetting labor supply response along this intensive margin is one-tenth of the demand effect of graduating in a recession, and thus graduating in a recession would be ten percent more painful had students not reallocated across majors. Relatedly, we find that a three percentage point rise in unemployment at the time of major choice leads to a distribution of majors that earns roughly 1.35 percent more, on average, for their long-run earnings. The results suggest that even brief recessions can have a long-lasting impact on the distribution of human capital in the economy and provide new insight into how labor supply adjusts in subtle ways to temporary disruptions in labor demand.

\footnotetext{
${ }^{34}$ On a related point, Jacobson, LaLonde and Sullivan (2005) find that displaced workers obtain sizable returns to math and science community college courses, and that the return is more than twice as large for women.
} 


\section{References}

Altonji, Joseph, "The Demand for and Return to Education when Education Outcomes are Uncertain," Journal of Labor Economics, 1993, 11, 48-83.

Altonji, Joseph G, Erica Blom, and Costas Meghir, "Heterogeneity in Human Capital Investments: High School Curriculum, College Major, and Careers," Annual Review of Economics, 2012, 4 (1), 185-223.

, Lisa B Kahn, and Jamin D Speer, "Cashier or Consultant? Entry Labor Market Conditions, Field of Study, and Career Success," 2013. Yale University mimeo.

Arcidiacono, Peter, "Ability Sorting and the Returns to College Major," Journal of Econometrics, 2004, 121 (1), 343-375.

, Esteban M Aucejo, and V Joseph Hotz, "University differences in the graduation of minorities in STEM fields: Evidence from California," Technical Report, National Bureau of Economic Research Working Paper No. 187992013.

, V Joseph Hotz, and Songman Kang, "Modeling college major choices using elicited measures of expectations and counterfactuals," Journal of Econometrics, 2012, 166 (1), 3-16.

Barr, Andrew and Sarah E Turner, "Expanding Enrollments and Contracting State Budgets The Effect of the Great Recession on Higher Education," The ANNALS of the American Academy of Political and Social Science, 2013, 650 (1), 168-193.

Bedard, Kelly and Douglas A Herman, "Who goes to graduate/professional school? The importance of economic fluctuations, undergraduate field, and ability," Economics of Education Review, 2008, 27 (2), 197-210.

Beffy, Magali, Denis Fougere, and Arnaud Maurel, "Choosing the field of study in postsecondary education: do expected earnings matter?," Review of Economics and Statistics, 2012, 94 (1), 334-347.

Berger, Mark C, "Predicted Future Earnings and Choice of College Major," Industrial and Labor Relations Review, 1988, pp. 418-429.

Bettinger, Eric P, Bridget Terry Long, Philip Oreopoulos, and Lisa Sanbonmatsu, "The Role of Application Assistance and Information in College Decisions: Results from the H\&R Block FAFSA Experiment," The Quarterly Journal of Economics, 2012, $127(3), 1205-1242$.

Betts, Julian R, "What do students know about wages? Evidence from a survey of undergraduates," Journal of Human Resources, 1996, pp. 27-56. 
and Laurel L McFarland, "Safe port in a storm: The impact of labor market conditions on community college enrollments," Journal of Human Resources, 1995, pp. 741765.

Bianchi, Nicola, "The General Equilibrium Effects of Educational Expansion," Technical Report, Stanford University Working Paper 2014.

Blau, Francine D. and Lawrence M. Kahn, "Changes in the Labor Supply Behavior of Married Women: 1980-2000," Journal of Labor Economics, 2007, 25 (3), pp. 393-438.

Blom, Erica, "Labor Market Determinants of College Major," Manuscript, November, 2012.

Bound, John, Michael Lovenheim, and Sarah Turner, "Why have college completion rates declined? An analysis of changing student preparation and collegiate resources," Technical Report, National Bureau of Economic Research Working Paper No. 15566 2009.

Brown, Charles and Mary Corcoran, "Sex-Based Differences in School Content and the Male-Female Wage Gap," Journal of Labor Economics, 1997, 15 (3), 431-65.

Caballero, Ricardo J and Mohamad L Hammour, "The Cleansing Effect of Recessions," American Economic Review, 1994, 84 (5), 1350-68.

Cadena, Brian C. and Benjamin J. Keys, "Human Capital and the Lifetime Costs of Impatience," American Economic Journal: Economic Policy, forthcoming.

Carneiro, Pedro and James J Heckman, "The Evidence on Credit Constraints in PostSecondary Schooling," The Economic Journal, 2002, 112 (482), 705-734.

_ _ _ a a _ Edward J Vytlacil, "Estimating Marginal Returns to Education," The American Economic Review, 2011, 101 (6), 2754-2781.

Charles, Kerwin K, Erik Hurst, and Matthew J Notowidigdo, "Housing Booms, Labor Market Outcomes, and Educational Attainment," Manuscript, University of Chicago, 2014.

Christian, Michael S, "Liquidity constraints and the cyclicality of college enrollment in the United States," Oxford Economic Papers, 2006.

Cunha, Flavio, James J. Heckman, Lance Lochner, and Dimitriy V. Masterov, "Interpreting the Evidence on Life Cycle Skill Formation," in E. Hanushek and F. Welch, eds., Handbook of the Economics of Education, Vol. 1, Elsevier, 2006, chapter 12, pp. 697 $-812$.

Currie, Janet and Hannes Schwandt, "Short-and long-term effects of unemployment on fertility," Proceedings of the National Academy of Sciences, 2014, 111 (41), 14734-14739. 
Davis, Steven J and John Haltiwanger, "Gross job creation and destruction: Microeconomic evidence and macroeconomic implications," in "NBER Macroeconomics Annual 1990, Volume 5," MIT Press, 1990, pp. 123-186.

Dellas, Harris and Plutarchos Sakellaris, "On the cyclicality of schooling: theory and evidence," Oxford Economic Papers, 2003, 55 (1), 148-172.

Dynarski, Susan, "Building the stock of college-educated labor," Journal of Human Resources, 2008, 43 (3), 576-610.

Ehrenberg, Ronald G, "Analyzing the Factors That Influence Persistence Rates in STEM Field, Majors: Introduction to the Symposium," Economics of Education Review, 2010, 29 (6), 888-891.

Field, Erica, "Educational Debt Burden and Career Choice: Evidence from a Financial Aid Experiment at NYU Law School," American Economic Journal: Applied Economics, 2009, 1 (1), 1-21.

Freeman, Richard B, "Cobweb Model of the Supply and Starting Salary of New Engineers, A," Indus. \&3 Lab. Rel. Rev., 1975, 29, 236.

Gemici, Ahu and Matthew Wiswall, "Evolution Of Gender Differences In PostSecondary Human Capital Investments: College Majors," International Economic Review, 2014, 55 (1), 23-56.

Giuliano, Paola and Antonio Spilimbergo, "Growing up in a Recession," The Review of Economic Studies, 2014, 81 (2), 787-817.

Goldin, Claudia and Lawrence F Katz, "The most egalitarian of all professions: Pharmacy and the evolution of a family-friendly occupation," Technical Report, National Bureau of Economic Research Working Paper No. 184102012.

Goldin, Claudia D., "Notes on Women and the Undergraduate Economics Major," CSWEP Newsletter, 2013, Summer, 4-6,15.

_ _ "A Pollution Theory of Discrimination: Male and Female Differences in Occupations and Earnings," 2014. Harvard University mimeo.

Goldin, Claudia Dale and Lawrence F Katz, The Race Between Education and Technology, Harvard University Press, 2009.

Grogger, Jeff and Eric Eide, "Changes in College Skills and the Rise in the College Wage Premium," Journal of Human Resources, 1995, pp. 280-310.

Hastings, Justine S, Christopher A Neilson, and Seth D Zimmerman, "Are some degrees worth more than others? evidence from college admission cutoffs in Chile," Technical Report, National Bureau of Economic Research Working Paper 192412013. 
Heckman, James J., "What Has Been Learned About Labor Supply in the Past Twenty Years?," The American Economic Review, 1993, 83 (2), pp. 116-121.

Hershbein, Brad J, "Graduating High School in a Recession: Work, Education, and Home Production," The BE Journal of Economic Analysis 85 Policy, 2012, 12 (1).

Hoxby, Caroline and Sarah Turner, "Expanding college opportunities for high-achieving, low income students," Stanford Institute for Economic Policy Research Discussion Paper, 2013, (12-014).

Hoynes, Hilary, Douglas L. Miller, and Jessamyn Schaller, "Who Suffers During Recessions?," The Journal of Economic Perspectives, 2012, 26 (3), 27-47.

Jacobson, Louis, Robert LaLonde, and Daniel G Sullivan, "Estimating the returns to community college schooling for displaced workers," Journal of Econometrics, 2005, 125 (1), 271-304.

Johnson, Matthew T., "The Impact of Business Cycle Fluctuations on Graduate School Enrollment," Economics of Education Review, 2013, 34, 122-134.

Kahn, Lisa B., "The Long-Term Labor Market Consequences of Graduating from College in a Bad Economy," Labour Economics, 2010, 17 (2), 303-316.

Killingsworth, Mark R. and James J. Heckman, "Female Labor Supply: A Survey," Handbook of labor economics, 1986, 1, 103-204.

Kirkebøen, Lars, Edwin Leuven, and Magne Mogstad, "Field of Study, Earnings, and Self-Selection," Technical Report, National Bureau of Economic Research Working Paper No. 208162014.

Light, Audrey and Wayne Strayer, "Determinants of college completion: School quality or student ability?," Journal of Human Resources, 2000, pp. 299-332.

Lochner, Lance and Alexander Monge-Naranjo, "Credit constraints in education," Technical Report, National Bureau of Economic Research 2011. w17435.

Long, Bridget Terry, "The Financial Crisis and Declining College Affordability: How Have Students and their Families Responded?," in J. Brown and C. Hoxby, eds., How the Great Recession Affected Higher Education, University of Chicago Press / NBER Conference Report, 2015.

Malamud, Ofer and Abigail Wozniak, "The Impact of College on Migration Evidence from the Vietnam Generation," Journal of Human resources, 2012, 47 (4), 913-950.

Malmendier, Ulrike and Stefan Nagel, "Depression Babies: Do Macroeconomic Experiences Affect Risk Taking?," Quarterly Journal of Economics, 2011, 126 (1). 
__ and __ , "Learning from Inflation Experiences," Quarterly Journal of Economics, 2015.

Montmarquette, Claude, Kathy Cannings, and Sophie Mahseredjian, "How do Young People Choose College Majors?," Economics of Education Review, 2002, 21 (6), $543-556$.

Oreopoulos, Philip, Till von Wachter, and Andrew Heisz, "The Short- and LongTerm Career Effects of Graduating in a Recession," American Economic Journal: Applied Economics, 2012, 4 (1), 1-29.

Oyer, Paul, "Initial Labor Market Conditions and Long-Term Outcomes for Economists," Journal of Economic Perspectives, Summer 2006, 20 (3), 143-160.

, "The Making of an Investment Banker: Macroeconomic Shocks, Career Choice, and Lifetime Income," The Journal of Finance, 2008, 63 (6), 2.

Rothstein, Jesse and Cecilia Elena Rouse, "Constrained after college: Student loans and early-career occupational choices," Journal of Public Economics, 2011, 95 (1), 149163.

Ruggles, Steven, J. Trent Alexander, Katie Genadek, Ronald Goeken, Matthew B. Schroeder, and Matthew Sobek, "Integrated Public Use Microdata Series: Version 5.0," 2010. Machine-readable database. Minneapolis: University of Minnesota.

Ruhm, Christopher J., "Are Recessions Good for Your Health?*," The Quarterly Journal of Economics, 2000, 115 (2), 617-650.

Sakellaris, Plutarchos and Antonio Spilimbergo, "Business cycles and investment in human capital: international evidence on higher education," in "Carnegie-Rochester Conference Series on Public Policy," Vol. 52 Elsevier 2000, pp. 221-256.

Spence, A. Michael, "Job Market Signaling," The Quarterly Journal of Economics, 1973, $87(3), 355-74$.

Stange, Kevin M., "An Empirical Investigation of the Option Value of College Enrollment," American Economic Journal: Applied Economics, 2012, 4 (1), 49-84.

Stinebrickner, Ralph and Todd Stinebrickner, "A Major in Science? Initial Beliefs and Final Outcomes for College Major and Dropout," The Review of Economic Studies, 2014, $81(1), 426-472$.

Stinebrickner, Todd and Ralph Stinebrickner, "Learning about Academic Ability and the College Dropout Decision," Journal of Labor Economics, 2012, 30 (4), 707-748. 
Turner, Sarah E and William G Bowen, "Choice of Major: The Changing (Unchanging) Gender Gap," Industrial and Labor Relations Review, 1999, pp. 289-313.

Wee, Shu Lin, "Born Under a Bad Sign: The Cost of Entering the Job Market During a Recession," 2013. University of Maryland mimeo.

Wiswall, Matthew and Basit Zafar, "Determinants of College Major Choice: Identification Using an Information Experiment," Review of Economic Studies, 2015, 82 (2), 791-824.

Zafar, Basit, "How do College Students Form Expectations?," Journal of Labor Economics, 2011, 29 (2), 301-348.

_ "College Major Choice and the Gender Gap," Journal of Human Resources, 2013, 48 (3), 545-595. 


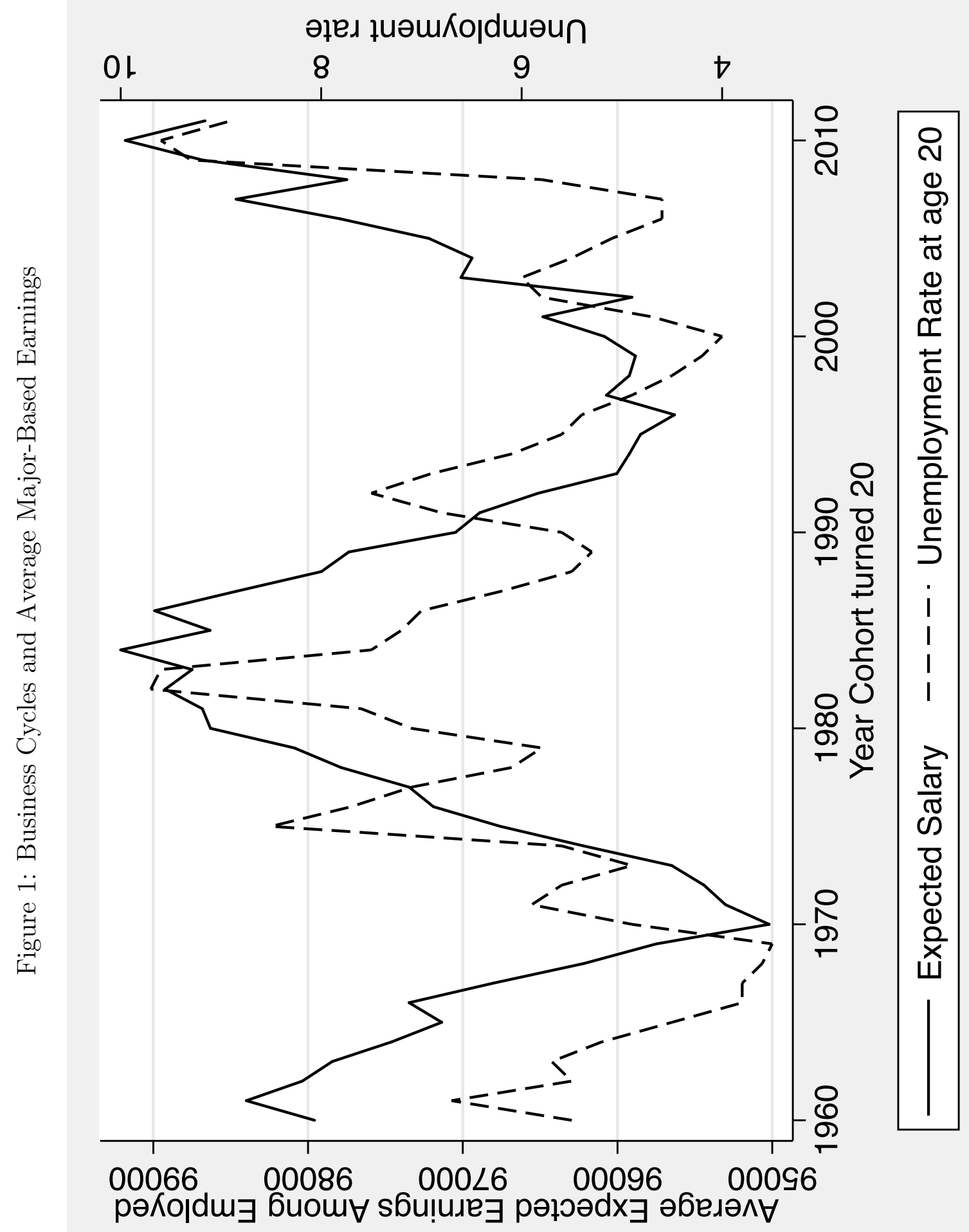

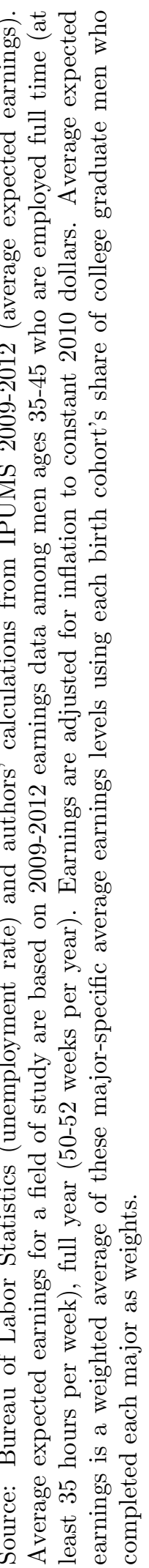


Figure 2: Example of Identifying Variation
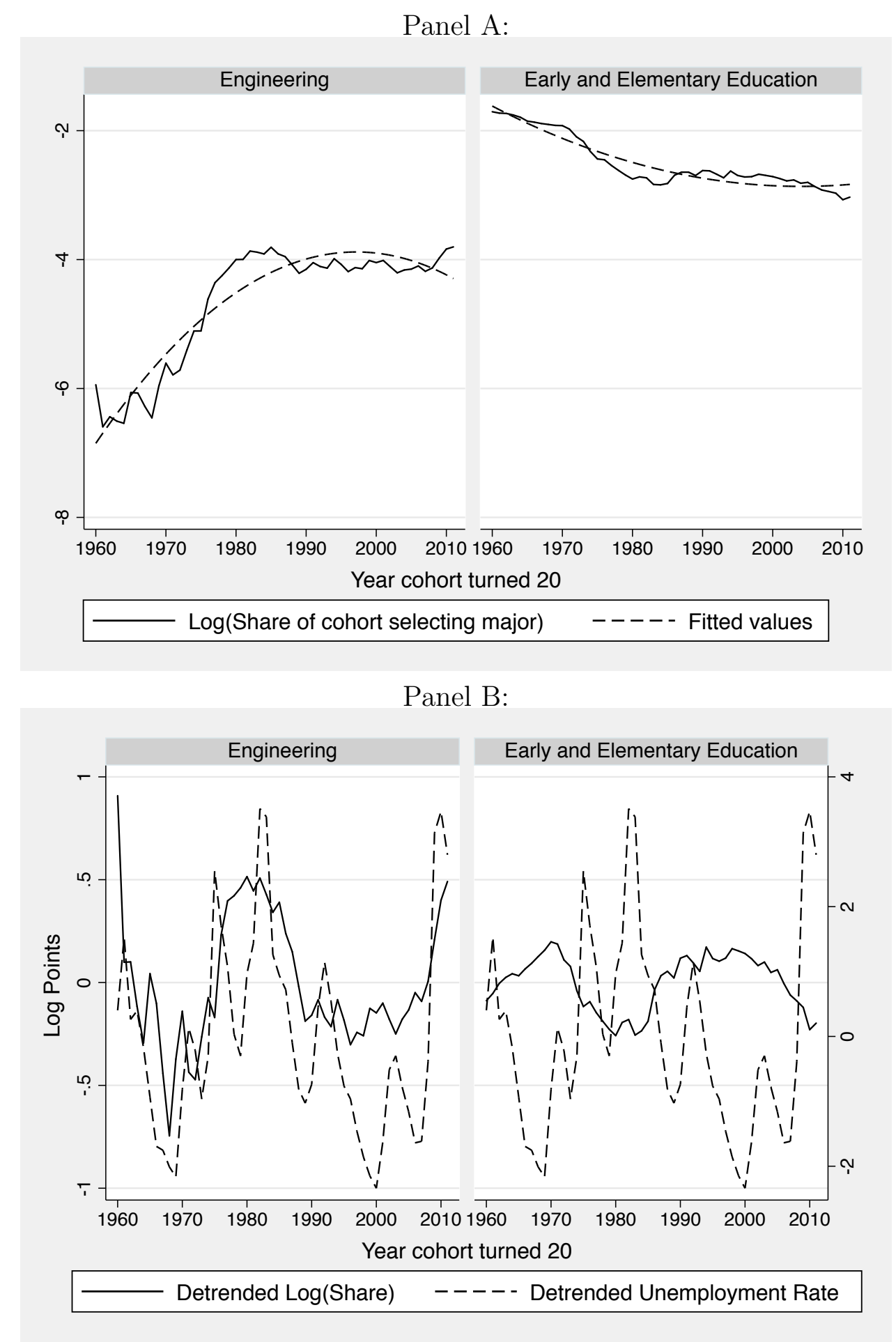

Data sources: BLS and authors' calculations from 2009-2012 ACS data. This analysis is based on the fields of study for birth cohorts of women who completed college degrees. Panel A shows the raw data and best fit quadratic trends for the log(share) of graduates completing degrees in Engineering and Early and Elementary Education. Panel B shows the time series of the residual log(share) variable after removing the trend as well as a similarly (quadratic) de-trended time series of the national unemployment rate. 


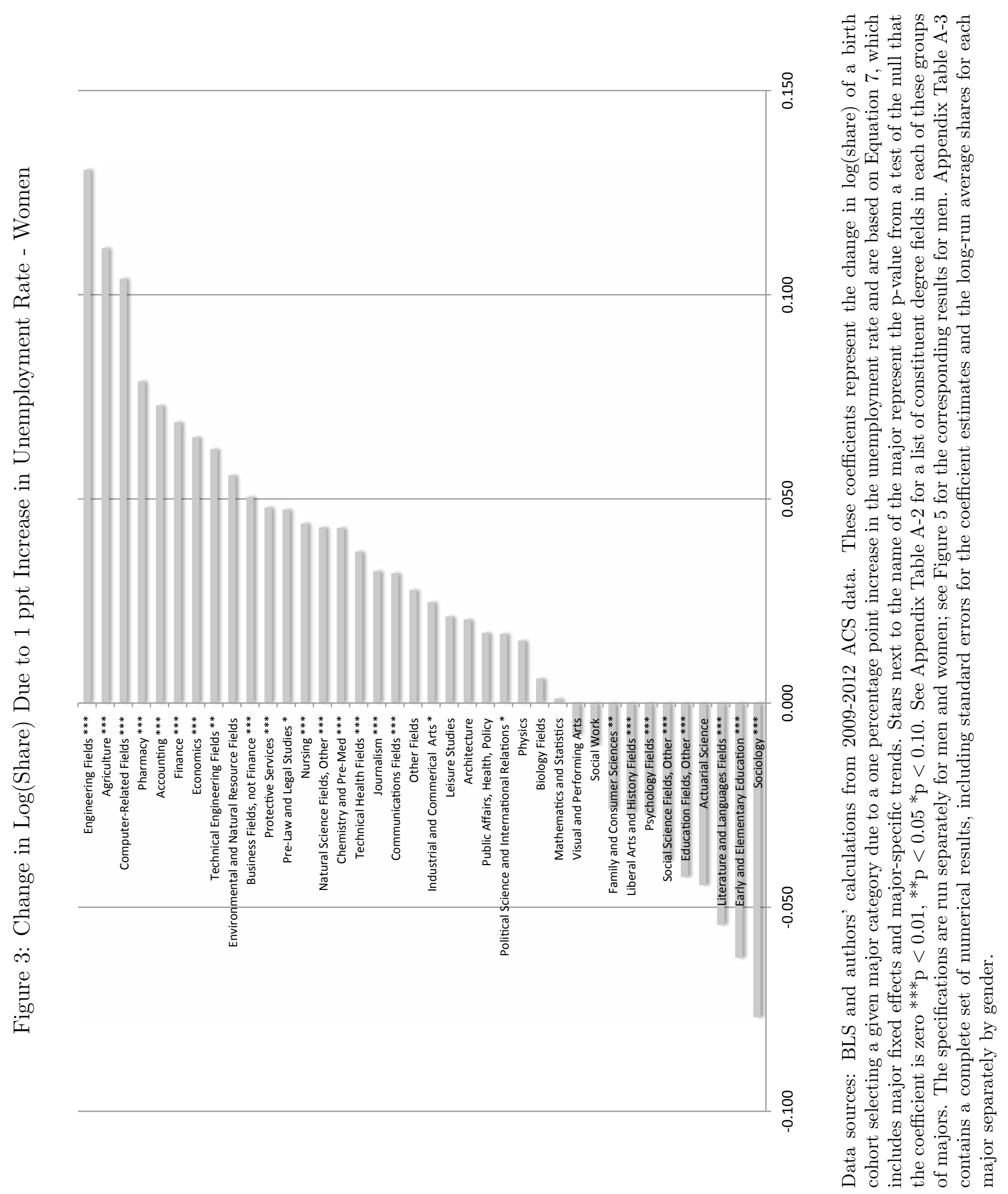




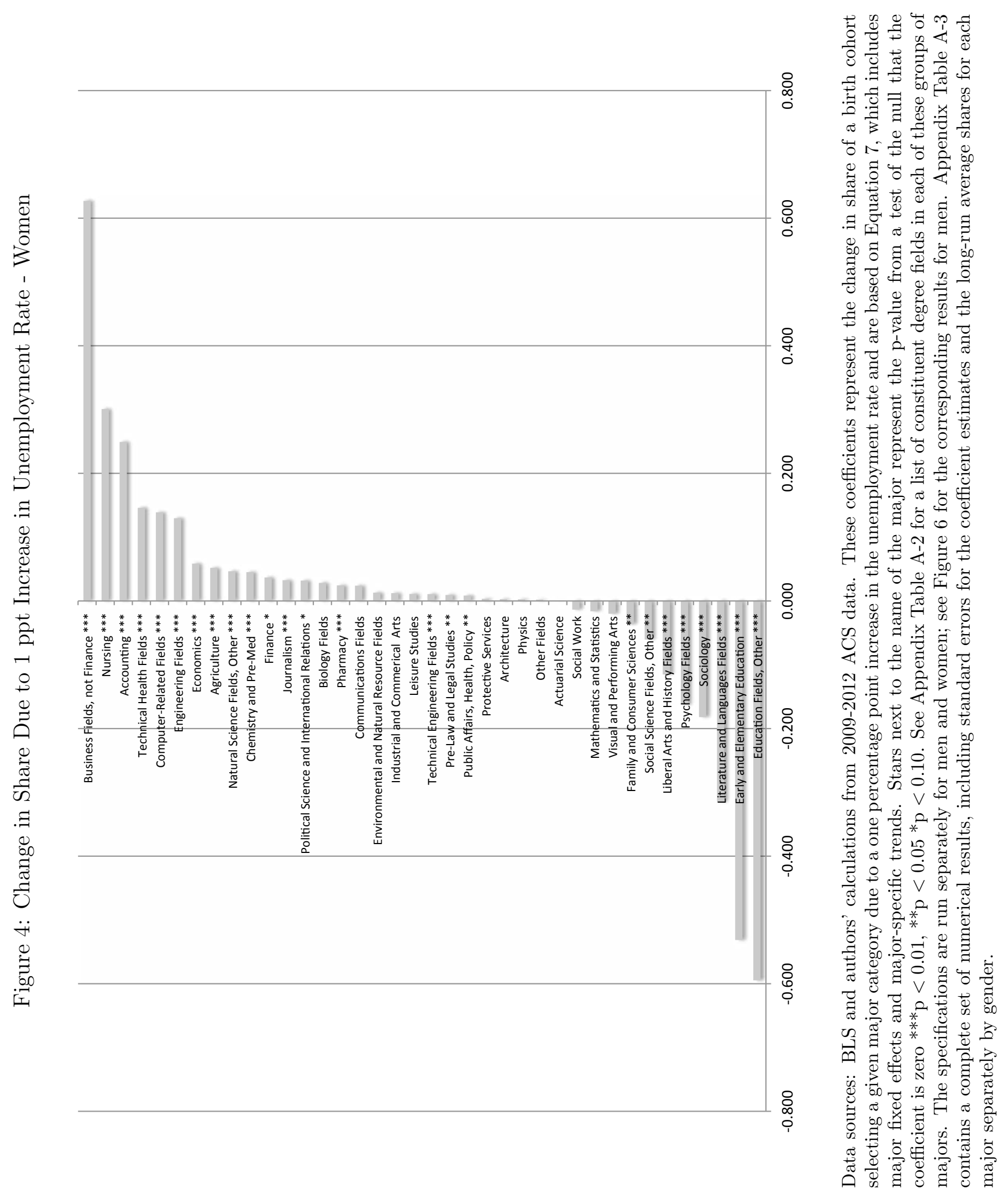




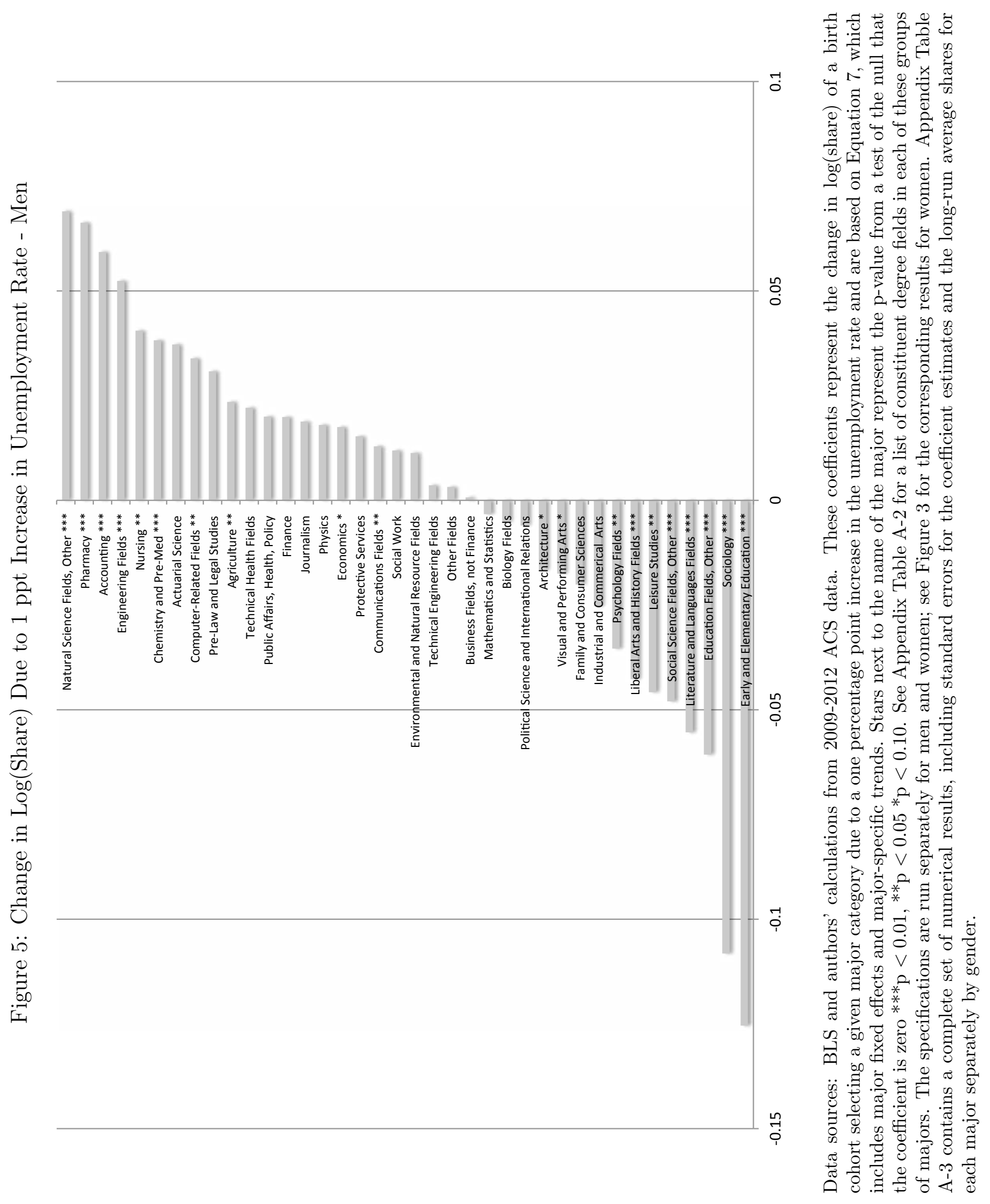



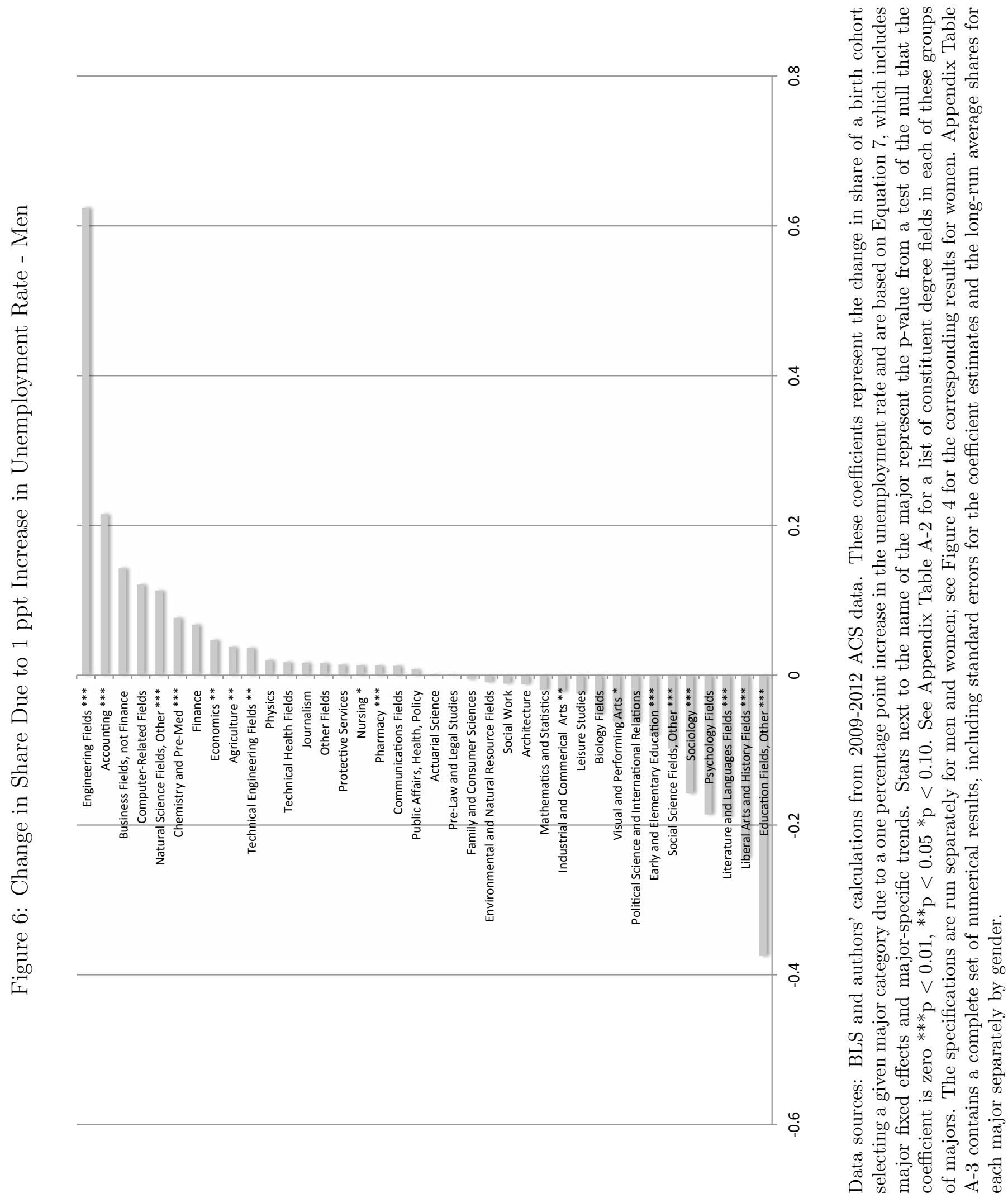
Figure 7: Relationship Between Long-Run Earnings and Major Share Cyclicality

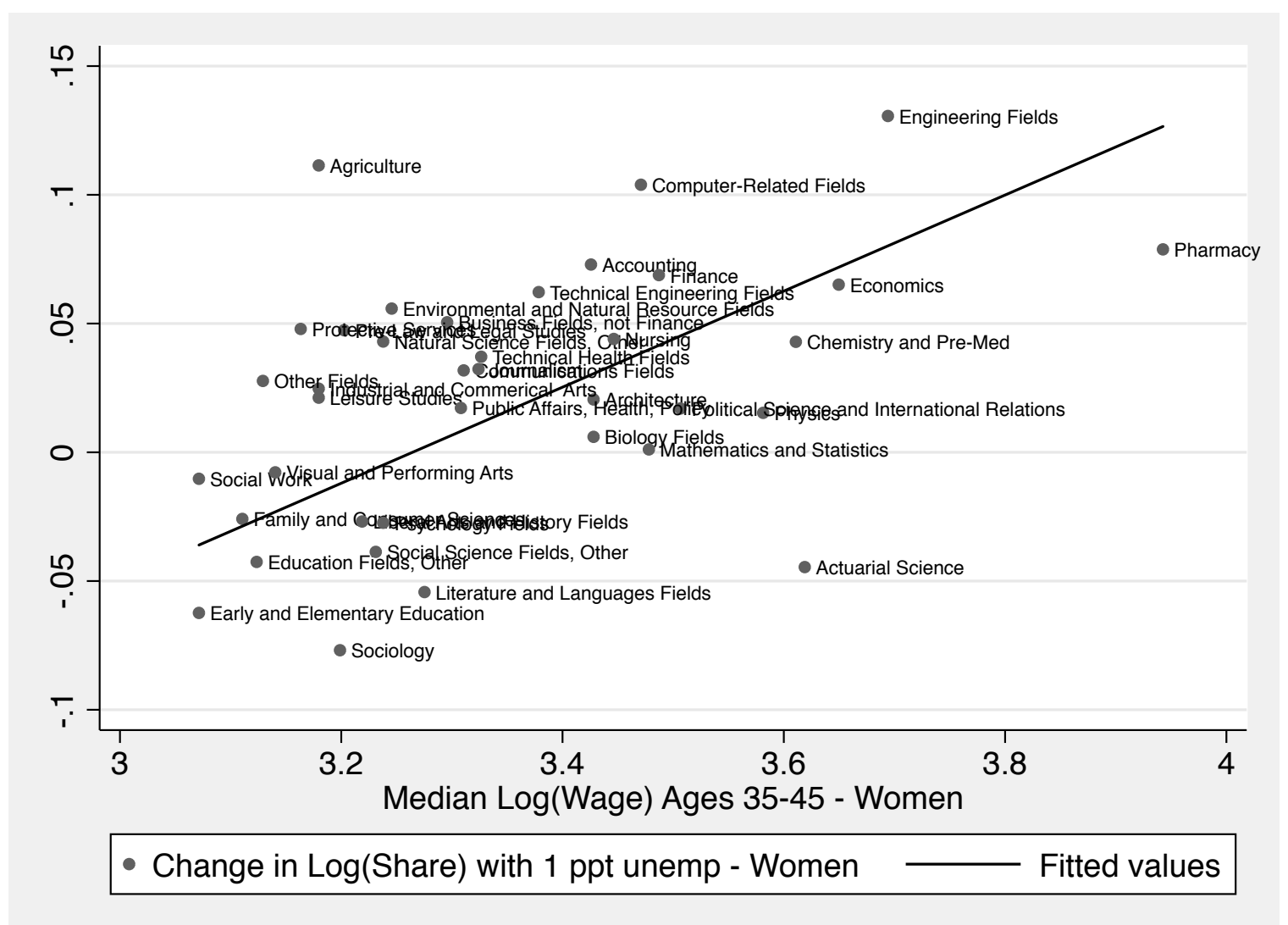

The dependent variable is the major-specific coefficient on the unemployment rate from the analysis in Figure 3. The fitted line represents the predicted values from an weighted regression, using the inverse of the sampling variance of the dependent variable (estimated using the bootstrapping procedure discussed in the text). Long-Run Earnings are the median $\log ($ earnings) of women ages 35-45 working full-time, full-year in 2009-2012. 
Table 1: Correlates of Cyclical Changes in Major Shares

\begin{tabular}{|c|c|c|c|c|}
\hline \multirow{2}{*}{$\begin{array}{l}\text { Characteristic of Major } \\
\text { Labor Market Prospects - Long Run }\end{array}$} & \multicolumn{2}{|c|}{ Women } & \multicolumn{2}{|c|}{ Men } \\
\hline & & & & \\
\hline Median Log(Wage) Ages 35-45 & $0.187 * * *$ & $(0.023)$ & $0.138 * * *$ & $(0.020)$ \\
\hline Share Working FTFY (35-45) & $0.489 * * *$ & (0.051) & $0.547 * * *$ & $(0.061)$ \\
\hline \multicolumn{5}{|l|}{ Labor Market Prospects - Short Run } \\
\hline Number of Job Interviews w/in first year & $0.015 * * *$ & $(0.002)$ & $0.011 * * *$ & $(0.003)$ \\
\hline Share Employed at 1 year & $0.361 * * *$ & (0.055) & $0.127^{* * *}$ & $(0.038)$ \\
\hline Share in Unrelated Jobs in first year & $-0.166 * * *$ & $(0.020)$ & $-0.142 * * *$ & $(0.017)$ \\
\hline \multicolumn{5}{|l|}{ Difficulty } \\
\hline Median SAT Math Score/100 & $0.045 * * *$ & (0.005) & $0.033 * * *$ & (0.004) \\
\hline Average Math GPA & $0.037 * * *$ & $(0.006)$ & $0.047 * * *$ & $(0.007)$ \\
\hline Average GPA for Major Courses & $-0.323 * * *$ & (0.038) & $-0.191 * * *$ & $(0.027)$ \\
\hline \multicolumn{5}{|l|}{ Other } \\
\hline Long-run average Female Share of Major & $-0.117 * * *$ & (0.015) & $-0.091 * * *$ & $(0.023)$ \\
\hline Share living in state of birth (Age 35-45) & $-0.113 * * *$ & (0.021) & -0.027 & (0.027) \\
\hline $\mathrm{HHI}$ of occupations (Age 35-45) & $-0.068 * * *$ & $(0.010)$ & -0.004 & $(0.026)$ \\
\hline Share with a grad degree (Age 35-45) & $-0.177 * * *$ & $(0.025)$ & $-0.051 * * *$ & $(0.017)$ \\
\hline
\end{tabular}

Authors' calculations from ACS and B\&B data. The dependent variable in each regression is the majorspecific coefficient on the unemployment rate from Equation 7 using $\log$ (Share) as the dependent variable. These coefficient estimates are available in Figures 3 and 5 , Earnings and FTFY are calculated separately by gender. All other variables are calculated based on all graduates in the major category. See Appendix Table A-2 for a list of majors. Regressions using major characteristics calculated from the ACS include all 38 majors. Regressions using B\&B characteristics have generally fewer observations due to data availability. Appendix Table A-5 provides summary statistics, including means, standard deviations and the number of valid observations for each of these characteristics. Observations are weighted by the inverse of the estimated variance of the dependent variable, which is calculated using the bootstrapping procedure described in the text. Bootstrapped standard errors in parentheses - see text for bootstrapping details. ${ }^{* * *} p<0.01$, ** $p<0.05,{ }^{*} p<0.1$ 


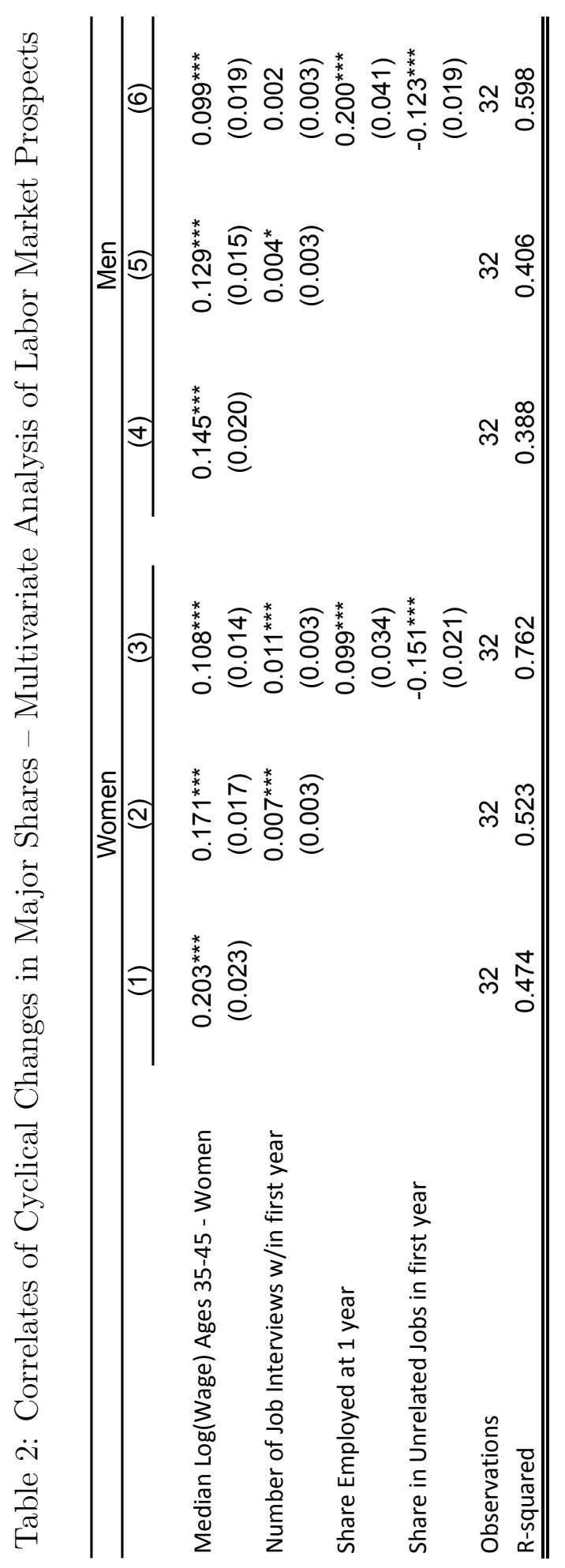

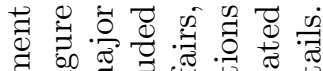

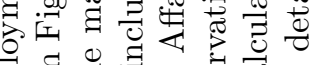

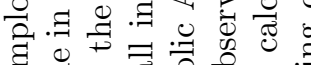

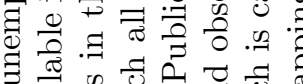

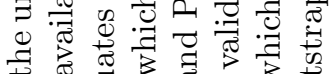

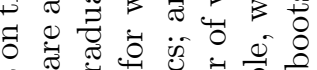

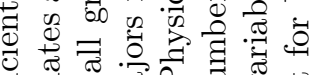

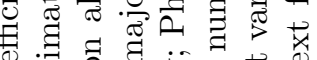

ठ

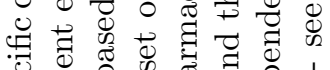

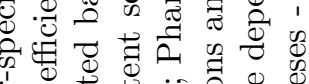

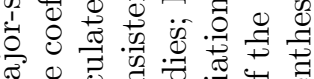

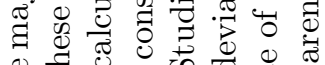

严

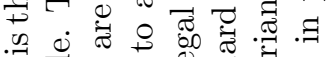

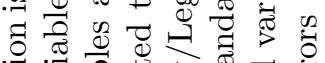

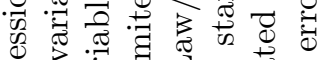

क्षे

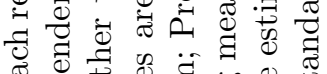

\&

.

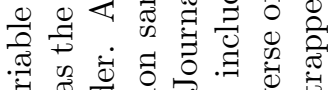

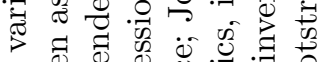

丮

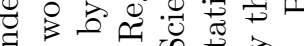

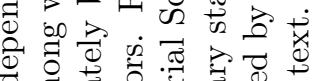

\&

E ठ

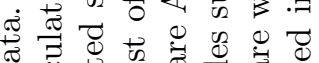

రิ

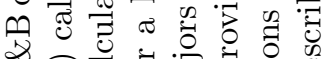

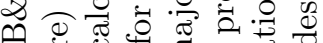

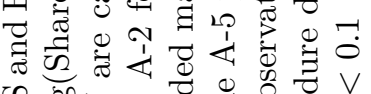

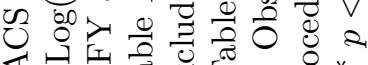

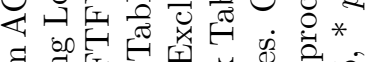

हี.

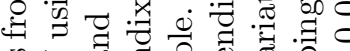

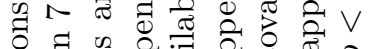

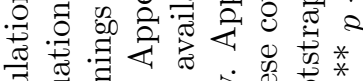

उ

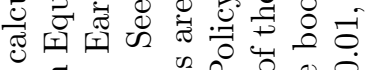

क्ञ̃

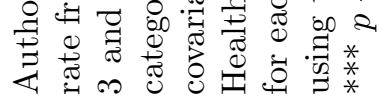


Table 3: Correlates of Cyclical Changes in Major Shares Conditional on Labor Market Prospects

\begin{tabular}{|c|c|c|c|c|}
\hline \multirow{3}{*}{$\begin{array}{l}\text { Characteristic of Major } \\
\text { Labor Market Prospects - Long Run } \\
\text { Share Working FTFY (35-45) }\end{array}$} & \multicolumn{2}{|c|}{ Women } & \multicolumn{2}{|c|}{ Men } \\
\hline & & & & \\
\hline & $0.184 * * *$ & $(0.037)$ & $0.167 * * *$ & $(0.061)$ \\
\hline \multicolumn{5}{|l|}{ Difficulty } \\
\hline Median SAT Math Score/100 & $-0.011 * *$ & $(0.005)$ & $-0.011 * *$ & $(0.004)$ \\
\hline Average Math GPA & $-0.030 * * *$ & (0.007) & $-0.051 * * *$ & $(0.008)$ \\
\hline Average GPA for Major Courses & $-0.181 * * *$ & $(0.032)$ & $-0.120 * * *$ & $(0.022)$ \\
\hline \multicolumn{5}{|l|}{ Other } \\
\hline Long-run average Female Share of Major & $-0.092 * * *$ & (0.018) & $-0.054 * * *$ & $(0.017)$ \\
\hline Share living in state of birth (Age 35-45) & 0.040 & $(0.038)$ & 0.031 & (0.036) \\
\hline HHI of occupations (Age 35-45) & $-0.047^{* *}$ & $(0.026)$ & $-0.060 * * *$ & $(0.020)$ \\
\hline Share with a grad degree (Age 35-45) & $-0.143 * * *$ & $(0.019)$ & $-0.070 * * *$ & $(0.022)$ \\
\hline
\end{tabular}

Authors' calculations from ACS and B\&B data. The dependent variable in each regression is the majorspecific coefficient on the unemployment rate from Equation 7 using $\log ($ Share) as the dependent variable. These coefficient estimates are available in Figure 3 and 5. Earnings and FTFY are calculated separately by gender. All other variables are calculated based on all graduates in the major category. See Appendix Table A-2 for a list of majors. Regression samples are limited to a consistent set of majors for which all included covariates are available. Excluded majors are Actuarial Science; Journalism; Pre-Law/Legal Studies; Pharmacy; Physics; and Public Affairs, Health, Policy. Appendix Table A-5 provides summary statistics, including means, standard deviations and the number of valid observations for each of these covariates. Observations are weighted by the inverse of the estimated variance of the dependent variable, which is calculated using the bootstrapping procedure described in the text. Bootstrapped standard errors in parentheses - see text for bootstrapping details. ${ }^{* * *} p<0.01,{ }^{* *} p<0.05,{ }^{*} p<0.1$ 


\section{Appendix - For Online Publication}

\section{A-1 Major-Specific Time Trends - Robustness}

In this appendix section, we discuss the robustness of our choice of quadratic major-specific time trends in our empirical specification. The goal of the time trends is to capture structural shifts in both higher education and the labor market over our time period of more than 50 years. These shifts are by construction intended to be slower moving than that of the business cycle, as we attempt to isolate cyclical from structural fluctuations. In capturing these trends over time, we face a tradeoff between under-fitting and over-fitting the data. If we underfit the data, say with a linear trend, then we may attribute too much of the variation over time to cyclical fluctuations, whereas an extremely flexible trend will remove both slower moving and cyclical variation over time.

Our preferred specification, used throughout the paper, is to include a quadratic majorspecific time trend in our estimates, as we show in the main text in Figure 2 for female engineering and early/elementary education majors. Appendix Figure A-2 replicates this figure to present a sensitivity analysis of this choice of time trend. The left panels of the figure show parametric alternatives, namely linear and cubic specifications. The linear option appears to dramatically underfit the trends in both cases, while the cubic looks quite similar to the quadratic specification. The right panels of Figure A-2 show three non-parametric alternatives, with bandwidths of 5, 7, and 9 years, respectively, to isolate trends that are slower-moving that most business cycles. Not surprisingly, as the bandwidth is reduces, we observe a closer fit to the overall trend for both engineering and early/elementary education majors.

Appendix Table A-1 formalizes this sensitivity analysis across all 38 majors in both the log-share (panel A) and share (panel B) regressions. The sample is of women with bachelor's degrees, and the quadratic time trend is the baseline used in the main text. The explanatory power of each specification is shown in the first three columns, as measured by the percent of variance explained by trends alone. Each specification results in 38 estimates of r-squared (one for each major), and we report the 25th, 50th, and 75th percentiles of the resulting distribution of r-squareds. The linear parametric trend and the 9-year bandwidth non-parametric trend each perform relatively poorly (as seen in the figures discussed above), while the other specifications have broadly similar explanatory power. In the next column, we estimate the magnitude of overall sensitivity to the business cycle, as measured by the sum of the absolute value of share coefficients. The 5-year bandwidth appears to absorb a great deal of the business cycle fluctuation, while the other five specifications yield broadly similar total sensitivity measures. The final column presents the correlation of major-specific estimates of business cycle sensitivity with the baseline quadratic trends specification. Similar to the previous column, the correlation is relatively weaker for the 5-year nonparametric specification, but extremely strong across the other specifications. In sum, the comparisons in this figure and table suggest that our results are quite robust to a range of methods for capturing long-term major-specific trends that are slower moving than the business cycle. 


\section{Figure A-1: Functional Form Comparison}
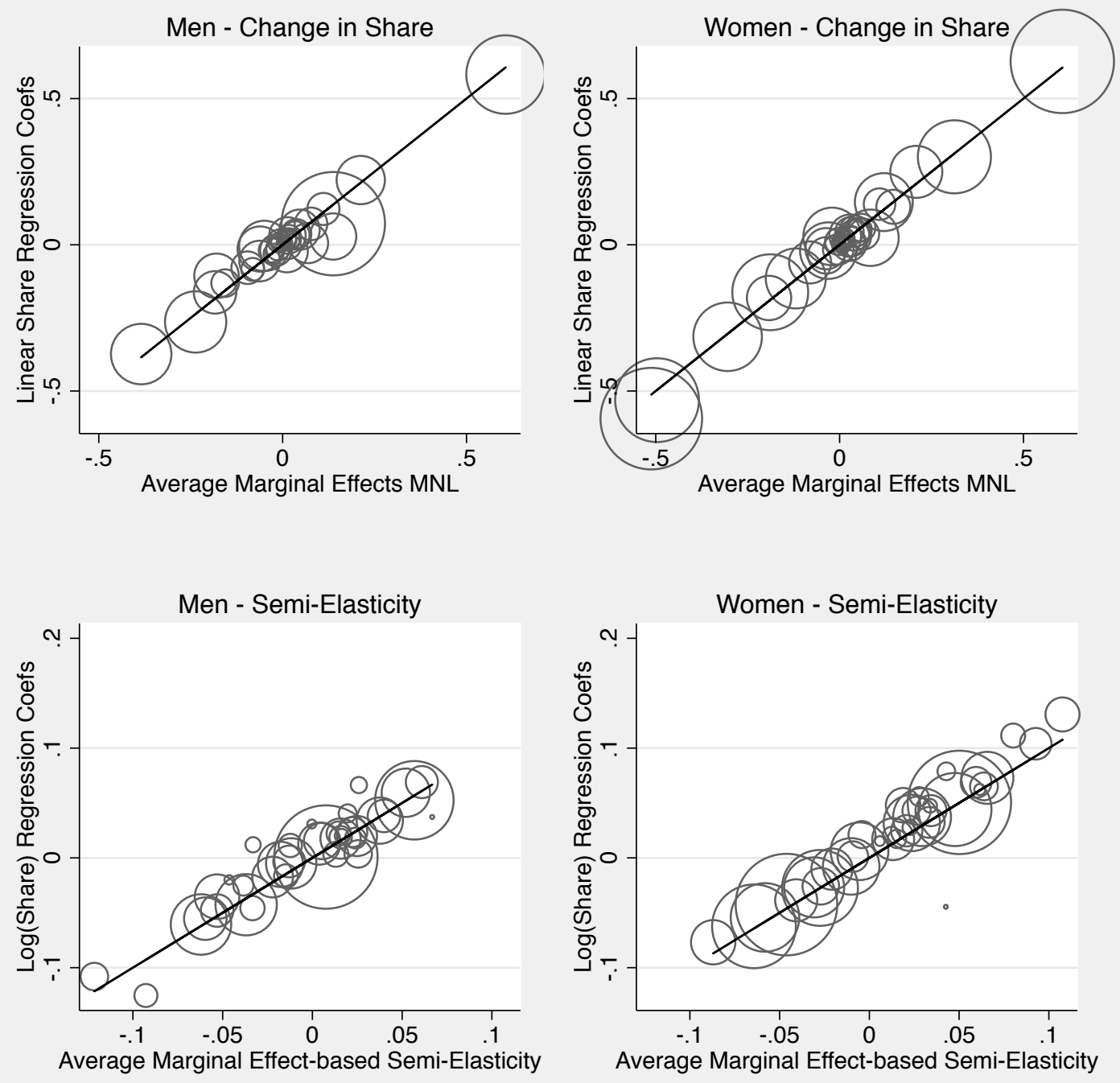

Each figure shows the estimated change in share or the estimated percentage change in share of graduates selecting a given major due to a 1 percentage point increase in the unemployment rate. The reference lines are 45-degree lines based on the multinomial logit (MNL) based specifications. For the "change in share" estimates, the MNL-based estimates represent average marginal effects. For the "Change in Log(Share)" estimates, the MNL-based estimates represent average marginal semi-elasticities. Each circle represents one major category, and the relative size of the circle represents the relative long-run average share of graduates selecting that major. The one major category with a wide discrepancy is actuarial science in the $\log (\mathrm{Share})$ specifications for women. This discrepancy is likely to the very small share of individuals selecting that major, and we omit this category for analysis based on the $\mathrm{B} \& \mathrm{~B}$ because there is no corresponding major category in that dataset. 
Figure A-2: Major-Specific Time Trend Comparison
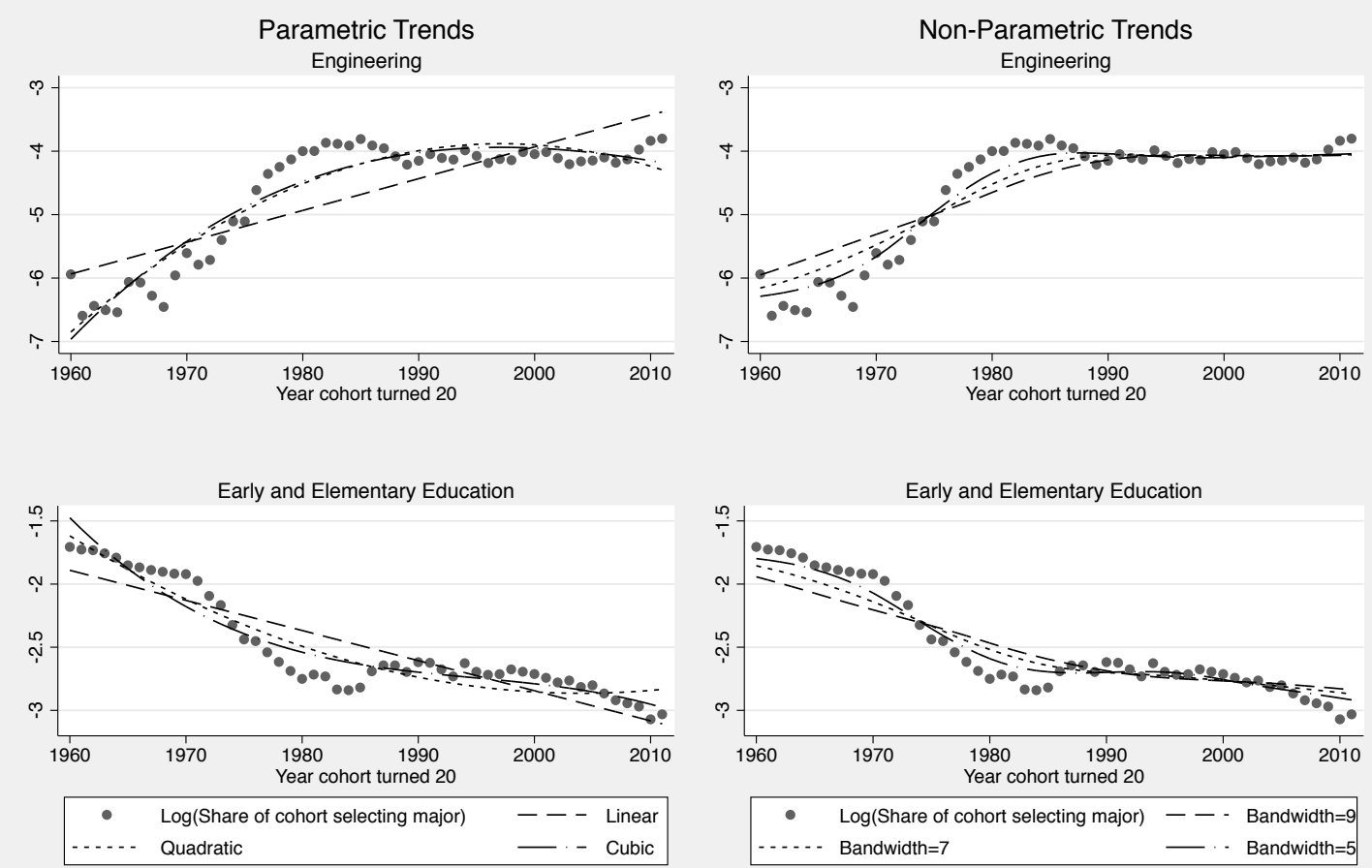

The four panels present sensitivity analysis to specifying major-specific time trends parametrically (left two panels) or non-parametrically (right two panels). The sample is of women with bachelor's degrees, the quadratic time trend is the baseline used in the main text. The two majors, engineering (top panels) and early/elementary education (bottom panels), are chosen to replicate those presented in Figure 2 
Table A-1: Major-Specific Time Trend Comparison

\begin{tabular}{|c|c|c|c|c|c|}
\hline \multirow[b]{3}{*}{$\begin{array}{l}\text { Panel A: Log(share) regressions } \\
\text { Parametric }\end{array}$} & \multicolumn{3}{|c|}{$\begin{array}{c}\text { Percent of Variance Explained by } \\
\text { trends alone }\end{array}$} & \multirow[t]{2}{*}{$\begin{array}{l}\text { Sum of absolute } \\
\text { value of coefs }\end{array}$} & \multirow[t]{2}{*}{$\begin{array}{l}\text { Correlation of Coefs with } \\
\text { Quadratic Trends Versior }\end{array}$} \\
\hline & 25th pctile & 50th pctile & 75th pctile & & \\
\hline & & & & & \\
\hline Linear & 0.338 & 0.568 & 0.809 & -- & 0.988 \\
\hline Quadratic & 0.607 & 0.814 & 0.882 & -- & 1.000 \\
\hline Cubic & 0.632 & 0.848 & 0.895 & -- & 0.962 \\
\hline \multicolumn{6}{|c|}{ Non-parametric } \\
\hline bw: 9 years & 0.539 & 0.692 & 0.820 & -- & 0.980 \\
\hline bw: 7 years & 0.661 & 0.799 & 0.879 & -- & 0.939 \\
\hline bw: 5 years & 0.757 & 0.879 & 0.932 & -- & 0.767 \\
\hline \multicolumn{6}{|c|}{ Panel B: share regressions } \\
\hline Linear & 0.293 & 0.549 & 0.850 & 5.04 & 0.996 \\
\hline Quadratic & 0.628 & 0.764 & 0.859 & 4.09 & 1.000 \\
\hline Cubic & 0.657 & 0.781 & 0.866 & 4.17 & 0.984 \\
\hline \multicolumn{6}{|c|}{ Non-parametric } \\
\hline bw: 9 years & 0.534 & 0.662 & 0.796 & 4.10 & 0.988 \\
\hline bw: 7 years & 0.628 & 0.764 & 0.859 & 2.86 & 0.961 \\
\hline bw: 5 years & 0.764 & 0.855 & 0.913 & 1.65 & 0.781 \\
\hline
\end{tabular}

The table presents sensitivity analysis to specifying major-specific time trends parametrically or nonparametrically in both the log-share (panel A) and share (panel B) regressions. The sample is of women with bachelor's degrees, and the quadratic time trend is the baseline used in the main text. The explanatory power of each specification is shown in the first three columns, as measured by the percent of variance explained by trends alone. Each specification results in 38 estimates of r-squared (one for each major), and we report the $25 \mathrm{th}, 50 \mathrm{th}$, and 75 th percentiles of the resulting distribution of r-squareds. In the next column, we estimate the magnitude of overall sensitivity to the business cycle, as measured by the sum of the absolute value of share coefficients. The final column presents the correlation of major-specific estimates of business cycle sensitivity with the baseline quadratic trends specification. 
Table A-2: Components of Major Categories Used in Analysis

\begin{tabular}{|c|c|c|}
\hline $\begin{array}{l}\text { Consistent Major } \\
\text { Category }\end{array}$ & B\&B components & ACS components \\
\hline Accounting & Accounting & Accounting \\
\hline Actuarial Science & $\mathrm{N} / \mathrm{A}$ & Actuarial Science \\
\hline \multicolumn{3}{|l|}{ Agriculture } \\
\hline & Agriculture & \\
\hline & Agricultural Science & \\
\hline & & General Agriculture \\
\hline & & Agriculture Production and Management \\
\hline & & Agricultural Economics \\
\hline & & Animal Sciences \\
\hline & & Food Science \\
\hline & & Plant Science and Agronomy \\
\hline & & Soil Science \\
\hline & & Miscellaneous Agriculture \\
\hline Architecture & Architecture & Architecture \\
\hline \multicolumn{3}{|l|}{ Biology Fields } \\
\hline & Bio Sci: Botany & Botany \\
\hline & Bio Sci: Zoology & Zoology \\
\hline & Bio Sci: all other & \\
\hline & & Ecology \\
\hline & & Pharmacology \\
\hline & & Miscellaneous Biology \\
\hline & & Biology \\
\hline & & Molecular Biology \\
\hline & & Genetics \\
\hline & & Microbiology \\
\hline & & Physiology \\
\hline & Interdisciplinary: Biopsychology & Cognitive Science and Biopsychology \\
\hline & & Neuroscience \\
\hline \multicolumn{3}{|l|}{ Business Fields, not } \\
\hline \multicolumn{3}{|l|}{ Finance } \\
\hline & Business/Management Systems & Management Information Systems and Statistics \\
\hline & Management/Business Administration & Business Management and Administration \\
\hline & Marketing/Distribution & Marketing and Marketing Research \\
\hline & Health: Health/Hospital Administration & Miscellaneous Business and Medical Administration \\
\hline & Secretarial & \\
\hline & Business Support & \\
\hline & & General Business \\
\hline & & Operations, Logistics and E-Commerce \\
\hline & & Business Economics \\
\hline & & Human Resources and Personnel Management \\
\hline & & International Business \\
\hline & & Hospitality Management \\
\hline \multicolumn{3}{|c|}{ Chemistry and Pre-Med } \\
\hline & Bio Sci: Biochemistry & Biochemical Sciences \\
\hline & Physical Sci: Chemistry & Chemistry \\
\hline & & Health and Medical Preparatory Programs \\
\hline
\end{tabular}

The farthest left column lists the major category used for analysis in the paper. The second column lists the constituent fields of study identified in the ACS. The final column lists the constituent majors identified in the B\&B. Original codes from the two datasets that appear to match exactly are listed in the same row. 
Table A-2: Components of Major Categories Used in Analysis, con't

\begin{tabular}{|c|c|c|}
\hline $\begin{array}{l}\text { Consistent n } \\
\text { Category }\end{array}$ & B\&B components & ACS components \\
\hline \multicolumn{3}{|c|}{ Communications Fields } \\
\hline & Communications & Communications \\
\hline & Communication Technology & Communication Technologies \\
\hline & & Mass Media \\
\hline & & Advertising and Public Relations \\
\hline \multicolumn{3}{|c|}{ Computer-Related Fields } \\
\hline & Computer Programming & Computer Programming and Data Processing \\
\hline & Computer and Information Sciences & \\
\hline & & Computer and Information Systems \\
\hline & & Computer Science \\
\hline & & Information Sciences \\
\hline & & Computer Information Management and Sec \\
\hline & & Computer Networking and Telecommunicati \\
\hline \multicolumn{3}{|c|}{ Early and Elementary } \\
\hline \multicolumn{3}{|c|}{ Education } \\
\hline & Education: Elementary & Elementary Education \\
\hline & Education: Early Childhood & Early Childhood Education \\
\hline Economics & Economics & Economics \\
\hline \multicolumn{3}{|c|}{ Education Fields, Other } \\
\hline & Education: Physical & Physical and Health Education Teaching \\
\hline & Education: Secondary & Secondary Teacher Education \\
\hline & Education: Special & Special Needs Education \\
\hline & Education: Other & Teacher Education: Multiple Levels \\
\hline & & Language and Drama Education \\
\hline & & General Education \\
\hline & & Educational Administration and Supervision \\
\hline & & School Student Counseling \\
\hline & & Mathematics Teacher Education \\
\hline & & Science and Computer Teacher Education \\
\hline & & Social Science or History Teacher Education \\
\hline & & Art and Music Education \\
\hline & & Miscellaneous Education \\
\hline & Library/Archival Science & Library Science \\
\hline
\end{tabular}

The farthest left column lists the major category used for analysis in the paper. The second column lists the constituent fields of study identified in the ACS. The final column lists the constituent majors identified in the B\&B. Original codes from the two datasets that appear to match exactly are listed in the same row. 


\section{Table A-2: Components of Major Categories Used in Analysis, con't}

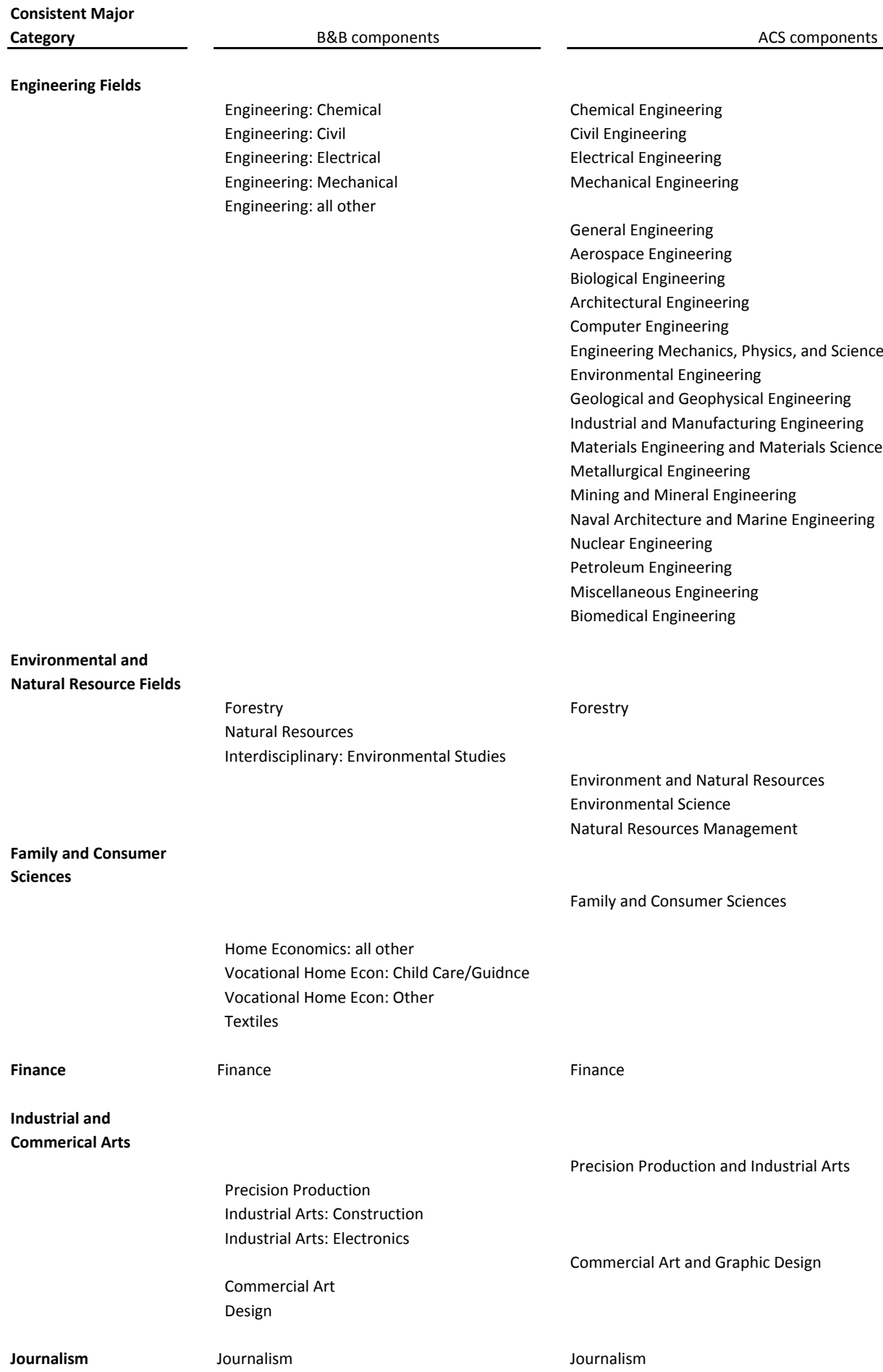

The farthest left column lists the major category used for analysis in the paper. The second column lists the constituent fields of study identified in the ACS. The final column lists the constituent majors identified in the B\&B. Original codes from the two datasets that appear to match exactly are listed in the same row. 


\section{Table A-2: Components of Major Categories Used in Analysis, con't}

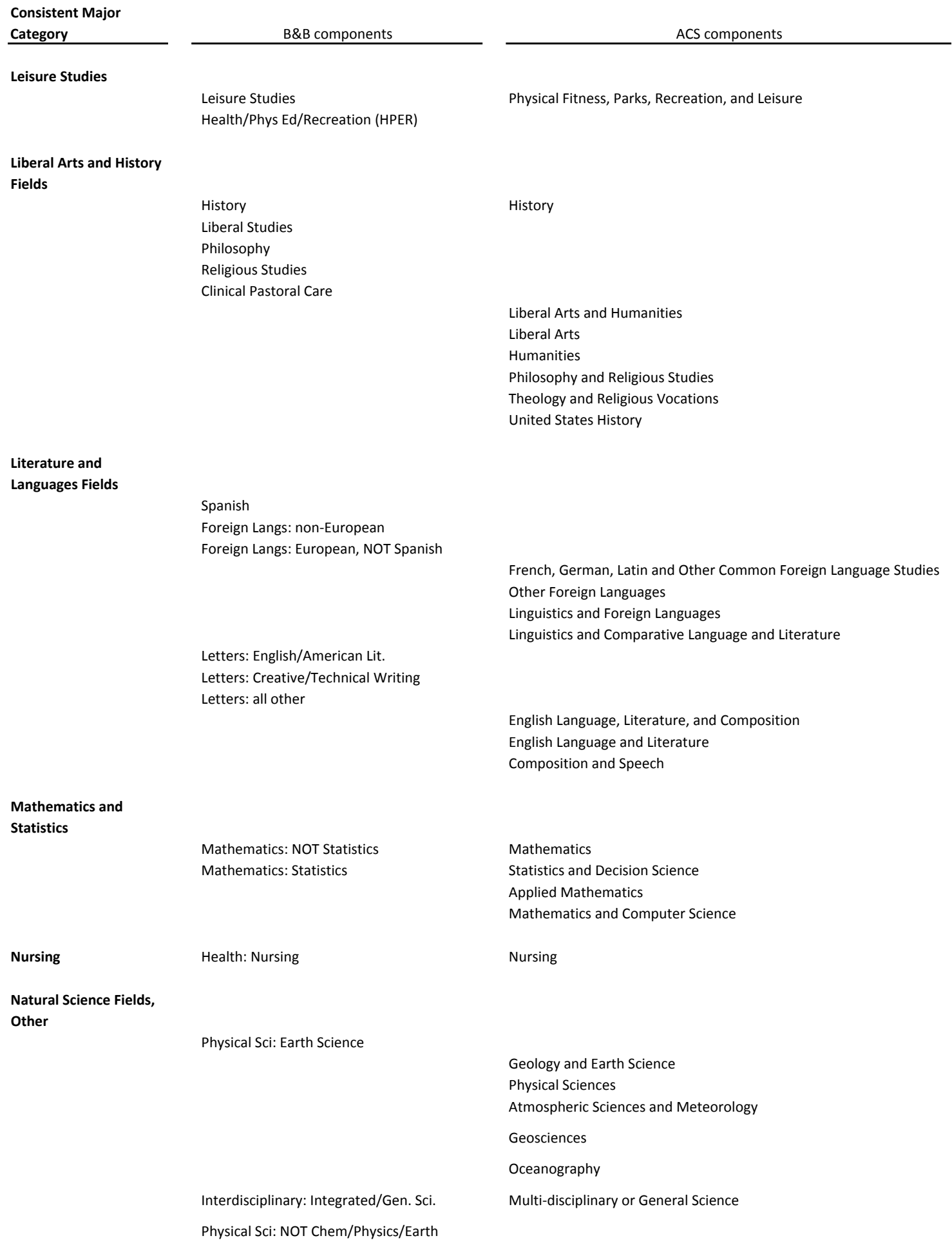

The farthest left column lists the major category used for analysis in the paper. The second column lists the constituent fields of study identified in the ACS. The final column lists the constituent majors identified in the B\&B. Original codes from the two datasets that appear to match exactly are listed in the same row. 
Table A-2: Components of Major Categories Used in Analysis, con’t

\begin{tabular}{|c|c|c|}
\hline $\begin{array}{l}\text { Consistent Major } \\
\text { Category }\end{array}$ & B\&B components & ACS components \\
\hline \multicolumn{3}{|l|}{ Other Fields } \\
\hline & Military Sciences & Military Technologies \\
\hline & Interdisciplinary: all other & Interdisciplinary and Multi-Disciplinary Studies (General) \\
\hline & & Transportation Sciences and Technologies \\
\hline & Transportation: Air & \\
\hline & Transportation: Not Air & \\
\hline & Basic/Personal Skills & \\
\hline & & Cosmetology Services and Culinary Arts \\
\hline & & Construction Services \\
\hline & & Electrical and Mechanic Repairs and Technologies \\
\hline \multicolumn{3}{|c|}{$\begin{array}{l}\text { Political Science and } \\
\text { International Relations }\end{array}$} \\
\hline & Political Science & Political Science and Government \\
\hline & International Relations & International Relations \\
\hline Pharmacy & N/A & Pharmacy, Pharmaceutical Sciences, and Administration \\
\hline \multicolumn{3}{|l|}{ Physics } \\
\hline & Physical Sci: Physics & \\
\hline & & Physics \\
\hline & & Astronomy and Astrophysics \\
\hline \multicolumn{3}{|l|}{ Pre-Law and Legal } \\
\hline \multicolumn{3}{|l|}{ Studies } \\
\hline & & Pre-Law and Legal Studies \\
\hline & & Court Reporting \\
\hline & Law: Paralegal, includes pre-Law & \\
\hline & Law & \\
\hline Protective Services & Protective Services & Criminal Justice and Fire Protection \\
\hline \multicolumn{3}{|l|}{ Psychology Fields } \\
\hline & Psychology & Psychology \\
\hline & & Educational Psychology \\
\hline & & Clinical Psychology \\
\hline & & Counseling Psychology \\
\hline & & Industrial and Organizational Psychology \\
\hline & & Social Psychology \\
\hline & & Miscellaneous Psychology \\
\hline \multicolumn{3}{|c|}{ Public Affairs, Health, } \\
\hline \multirow[t]{4}{*}{ Policy } & Public Administration, NOT Social Work & Public Administration \\
\hline & & Public Policy \\
\hline & & Community and Public Health \\
\hline & Health: Public Health & \\
\hline
\end{tabular}

The farthest left column lists the major category used for analysis in the paper. The second column lists the constituent fields of study identified in the ACS. The final column lists the constituent majors identified in the $\mathrm{B} \& \mathrm{~B}$. Original codes from the two datasets that appear to match exactly are listed in the same row. 


\section{Table A-2: Components of Major Categories Used in Analysis, con't}

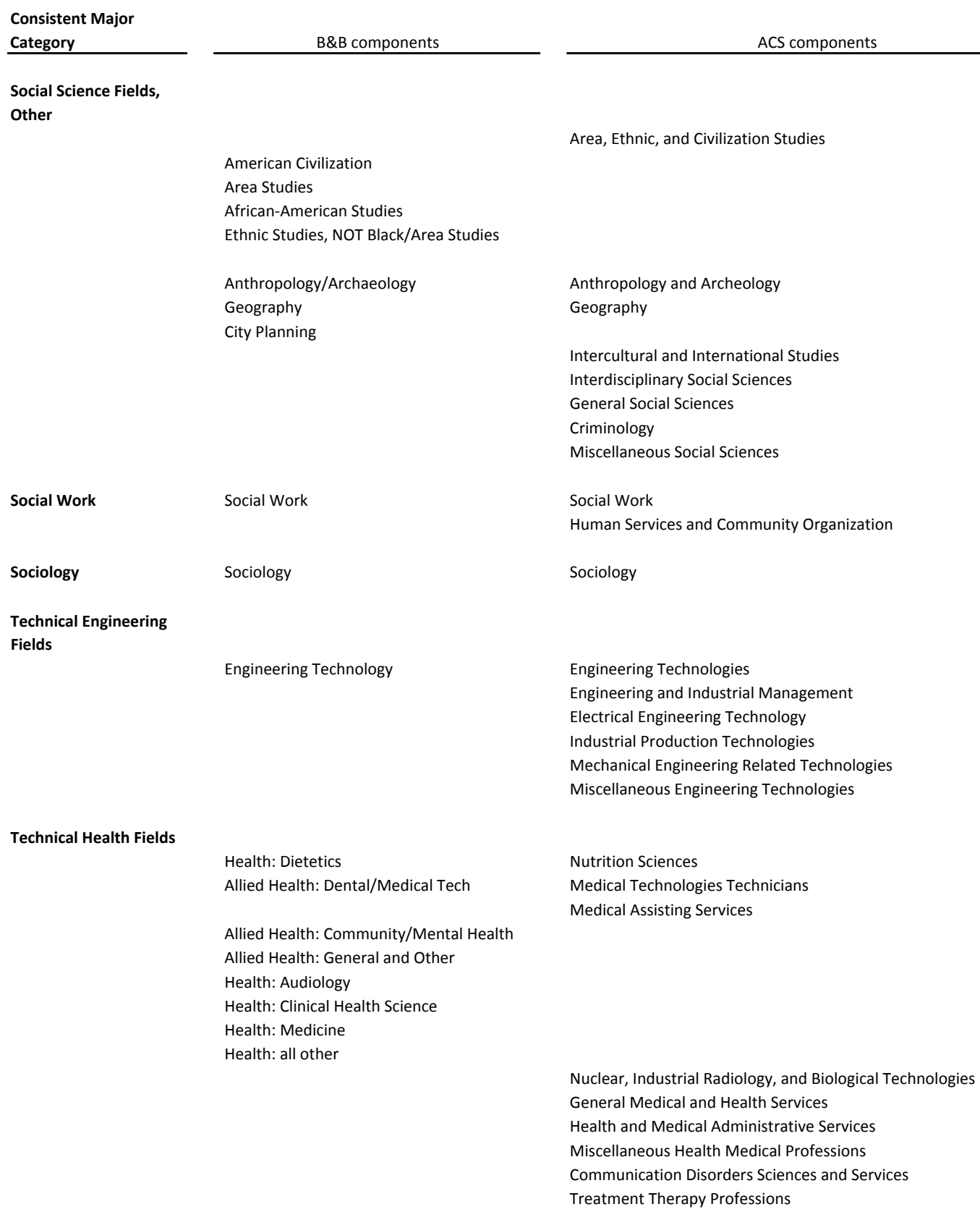

The farthest left column lists the major category used for analysis in the paper. The second column lists the constituent fields of study identified in the ACS. The final column lists the constituent majors identified in the B\&B. Original codes from the two datasets that appear to match exactly are listed in the same row. 
Table A-2: Components of Major Categories Used in Analysis, con't

\begin{tabular}{lll}
$\begin{array}{l}\text { Consistent Major } \\
\text { Category }\end{array}$ & \multicolumn{1}{c}{ B\&B components } & \multicolumn{1}{c}{ ACS components } \\
\cline { 1 - 1 } $\begin{array}{l}\text { Visual and Performing } \\
\text { Arts }\end{array}$ & & \\
& Art History/Fine Arts & \\
& & Art History and Criticism \\
& Music & Fine Arts \\
Speech/Drama & Music \\
& Film Arts & Drama and Theater Arts \\
& Fine and Performing Arts: all other & Miscellaneous Fine Arts \\
& Studio Arts \\
& Visual and Performing Arts
\end{tabular}

The farthest left column lists the major category used for analysis in the paper. The second column lists the constituent fields of study identified in the ACS. The final column lists the constituent majors identified in the B\&B. Original codes from the two datasets that appear to match exactly are listed in the same row. 


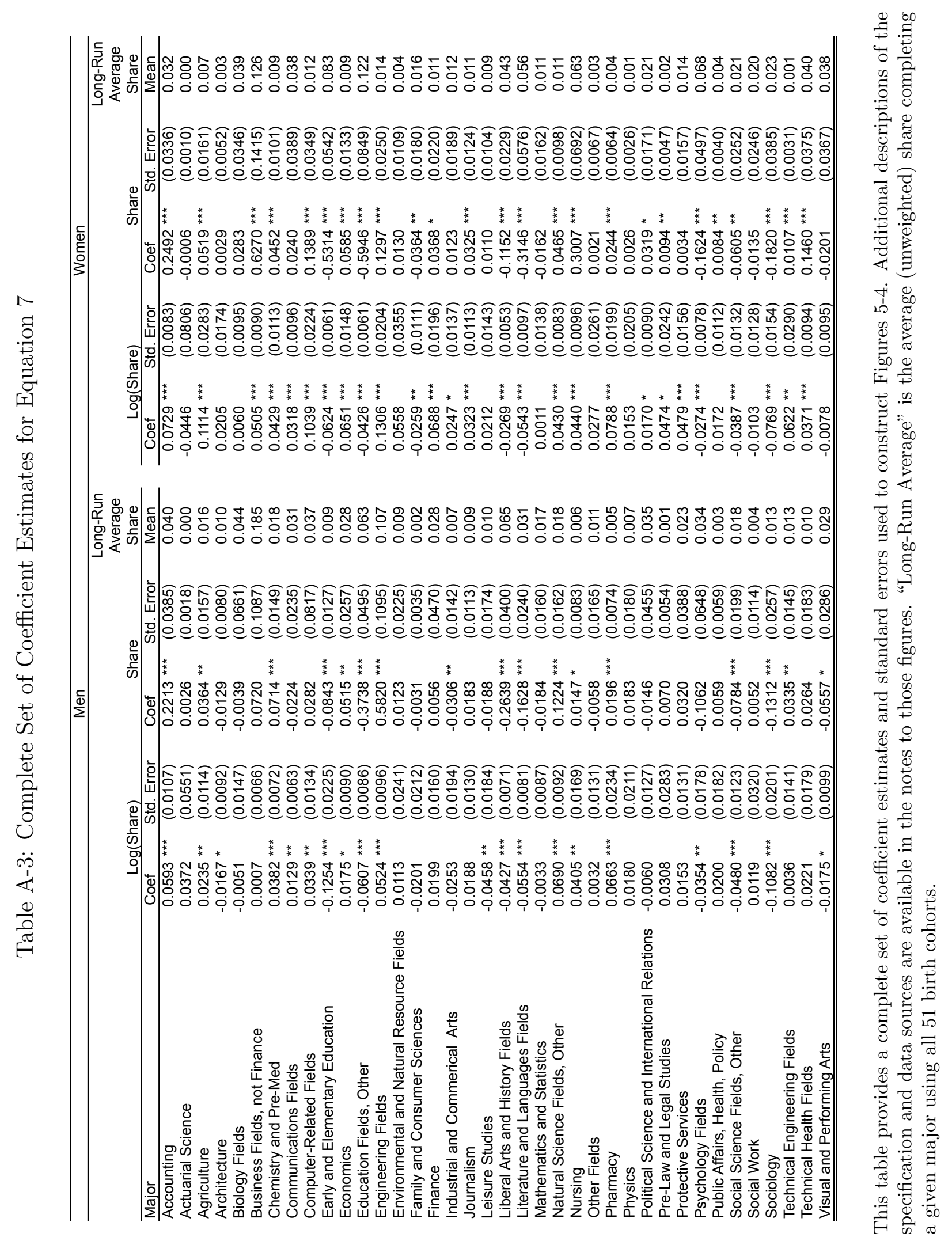


Table A-4: Gender Differences in Major Cyclicality

\begin{tabular}{|c|c|c|c|c|}
\hline & Men & Women & \multicolumn{2}{|c|}{ Difference } \\
\hline & Coef & Coef & Coef & S.E. \\
\hline Accounting & $0.0593^{* * *}$ & $0.0729 * * *$ & 0.0136 & $(0.0129)$ \\
\hline Actuarial Science & 0.0372 & -0.0446 & -0.0818 & $(0.1063)$ \\
\hline Agriculture & 0.0235 ** & $0.1114 * * *$ & $0.0879 * * *$ & $(0.0243)$ \\
\hline Architecture & $-0.0167 *$ & 0.0205 & 0.0372 ** & $(0.0186)$ \\
\hline Biology Fields & -0.0051 & 0.0060 & 0.0111 & $(0.0118)$ \\
\hline Business Fields, not Finance & 0.0007 & $0.0505^{* * *}$ & $0.0498 * * *$ & $(0.0072)$ \\
\hline Chemistry and Pre-Med & $0.0382 * * *$ & $0.0429 * * *$ & 0.0048 & $(0.0118)$ \\
\hline Communications Fields & $0.0129 * *$ & $0.0318^{* * *}$ & $0.0190 *$ & $(0.0101)$ \\
\hline Computer-Related Fields & $0.0339 * *$ & $0.1039 * * *$ & $0.0700 * * *$ & $(0.0177)$ \\
\hline Early and Elementary Education & $-0.1254 * * *$ & $-0.0624 * * *$ & $0.0630^{* * *}$ & $(0.0197)$ \\
\hline Economics & $0.0175^{*}$ & $0.0651^{* * *}$ & $0.0476 * * *$ & $(0.0150)$ \\
\hline Education Fields, Other & $-0.0607^{* * *}$ & $-0.0426 * * *$ & $0.0181 * * *$ & $(0.0051)$ \\
\hline Engineering Fields & $0.0524^{* * *}$ & $0.1306^{* * *}$ & $0.0782 * * *$ & $(0.0138)$ \\
\hline Environmental and Natural Resource Fields & 0.0113 & 0.0558 & $0.0444 *$ & $(0.0253)$ \\
\hline Family and Consumer Sciences & -0.0201 & $-0.0259 * *$ & -0.0058 & $(0.0236)$ \\
\hline Finance & 0.0199 & $0.0688^{* * *}$ & $0.0490^{* * *}$ & $(0.0132)$ \\
\hline Industrial and Commerical Arts & -0.0253 & $0.0247 *$ & $0.0501^{* * *}$ & $(0.0187)$ \\
\hline Journalism & 0.0188 & $0.0323^{* * *}$ & 0.0135 & $(0.0136)$ \\
\hline Leisure Studies & $-0.0458 * *$ & 0.0212 & $0.0669 * * *$ & $(0.0178)$ \\
\hline Liberal Arts and History Fields & $-0.0427^{* * *}$ & $-0.0269 * * *$ & $0.0158 *$ & $(0.0091)$ \\
\hline Literature and Languages Fields & $-0.0554 * * *$ & $-0.0543 * * *$ & 0.0011 & $(0.0072)$ \\
\hline Mathematics and Statistics & -0.0033 & 0.0011 & 0.0044 & $(0.0105)$ \\
\hline Natural Science Fields, Other & $0.0690 * * *$ & $0.0430 * * *$ & $-0.0260 * *$ & $(0.0121)$ \\
\hline Nursing & $0.0405^{* *}$ & $0.0440 * * *$ & 0.0035 & $(0.0163)$ \\
\hline Other Fields & 0.0032 & 0.0277 & 0.0245 & $(0.0317)$ \\
\hline Pharmacy & $0.0663^{* * *}$ & $0.0788 * * *$ & 0.0125 & $(0.0206)$ \\
\hline Physics & 0.0180 & 0.0153 & -0.0027 & $(0.0296)$ \\
\hline Political Science and International Relations & -0.0060 & $0.0170 *$ & 0.0230 & $(0.0143)$ \\
\hline Pre-Law and Legal Studies & 0.0308 & $0.0474 *$ & 0.0166 & $(0.0269)$ \\
\hline Protective Services & 0.0153 & $0.0479 * * *$ & $0.0326 *$ & $(0.0181)$ \\
\hline Psychology Fields & -0.0354 ** & $-0.0274^{* * *}$ & 0.0080 & $(0.0143)$ \\
\hline Public Affairs, Health, Policy & 0.0200 & 0.0172 & -0.0028 & $(0.0237)$ \\
\hline Social Science Fields, Other & $-0.0480 * * *$ & $-0.0387^{* * *}$ & 0.0093 & $(0.0084)$ \\
\hline Social Work & 0.0119 & -0.0103 & -0.0222 & $(0.0229)$ \\
\hline Sociology & $-0.1082 * * *$ & $-0.0769 * * *$ & $0.0313^{* *}$ & $(0.0148)$ \\
\hline Technical Engineering Fields & 0.0036 & 0.0622 ** & 0.0586 ** & $(0.0256)$ \\
\hline Technical Health Fields & 0.0221 & $0.0371^{* * *}$ & 0.0149 & $(0.0163)$ \\
\hline Visual and Performing Arts & $-0.0175 *$ & -0.0078 & 0.0097 & $(0.0090)$ \\
\hline
\end{tabular}

This table provides tests of the equality between genders of the $\log ($ share) coefficients presented in Appendix Table A-3. 
Table A-5: Descriptive Statistics for Correlates of Major Cyclicality

\begin{tabular}{llll}
\hline & $\mathrm{N}$ & Mean & Std. Dev. \\
\hline Panel A: Women & & & \\
ACS Variables & 38 & 0.003 & 0.045 \\
Change in Log(Share) with 1 ppt unemp - Women & 38 & 0.380 & 0.123 \\
Share with Graduate Degree (Age 35-45) & 38 & 0.598 & 0.186 \\
Long-run average Female Share of Major & 38 & 0.526 & 0.070 \\
Share living in state of birth (Age 35-45) & 38 & 0.100 & 0.129 \\
HHI of occupations (Age 35-45) & 38 & 3.280 & 0.163 \\
Median Log(Wage) Ages 35-45 - Women & 38 & 0.571 & 0.052 \\
Share Working FTFY (35-45) - Women & & & \\
B\&B Variables & 33 & 3.349 & 0.086 \\
Average GPA for Major Courses & 28 & 2.621 & 0.233 \\
Average Math GPA & 32 & 5.153 & 1.540 \\
Number of Job Interviews w/in first year & 31 & 5.316 & 0.423 \\
Median SAT Math Score/100 & 34 & 3.854 & 4.100 \\
Median Number of Math Credits & 34 & 0.845 & 0.052 \\
Share Employed at 1 year & 34 & 0.501 & 0.154 \\
Share in Unrelated Jobs in first year & & & \\
Panel B: Men & & & \\
ACS Variables & 38 & 0.001 & 0.039 \\
Change in Log(Share) with 1 ppt unemp - Men & 38 & 0.350 & 0.137 \\
Share with Graduate Degree (Age 35-45) & 38 & 0.482 & 0.165 \\
Long-run average Female Share of Major & 38 & 0.501 & 0.065 \\
Share living in state of birth (Age 35-45) & 38 & 0.058 & 0.082 \\
HHI of occupations (Age 35-45) & 38 & 3.507 & 0.173 \\
Median Log(Wage) Ages 35-45 - Men & 38 & 0.830 & 0.046 \\
Share Working FTFY (35-45) - Men & 33 & & \\
B\&B Variables & 38.314 & 0.091 \\
Average GPA for Major Courses & 38 & 2.635 & 0.247 \\
Average Math GPA & 31 & 5.968 & 1.465 \\
Number of Job Interviews w/in first year & 5.491 & 0.456 \\
Median SAT Math Score/100 & 34 & 5.693 & 6.001 \\
Median Number of Math Credits & 0.856 & 0.055 \\
Share Employed at 1 year & & & \\
Share in Unrelated Jobs in first year & 34.150 \\
\hline \hline
\end{tabular}

Source: Authors' calculations from ACS and B\&B data. Majors are weighted using the same weights as in Tables 1. 3, which are gender specific. These weights are not equal to the long-run shares of the major categories, which is why the weighted averages of the changes in $\log$ (share) are not equal to zero. The variables listed with "- Women" or "- Men" are calculated based on underlying data limited to the respective gender. The other variables are calculated using all available observations in the source datasets. Thus, any differences between panels for these variables reflect differences in weights. The first two rows of each panel summarize the major-specific coefficients on the unemployment rate estimated based on Equation 7 The number of observations varies in $\mathrm{B} \& \mathrm{~B}$ variables due to disclosure requirements. Calculations that would risk confidentiality were not provided by the online data extraction tool. 